\title{
Modelo de aproximación al comportamiento de la deserción voluntaria universitaria en pregrados de Ingeniería periodo 2015-2018
}

\author{
Behavior Approach Model of Voluntary University Desertion \\ in Undergraduate Programs in Engineering, Period 2015-2018
}

\author{
Mónica Lizeth Sánchez-Arévalo ${ }^{1} \bowtie$, Luisa Fernanda Cruz-Hueso², \\ Roberto Ferro-Escobar ${ }^{3}$
}

${ }^{1}$ Universidad Distrital Francisco José de Caldas, Bogotá, Colombia
${ }^{2}$ Universidad Distrital Francisco José de Caldas, Bogotá, Colombia
${ }^{3}$ Universidad Distrital Francisco José de Caldas, Bogotá, Colombia

$\triangle$ Universidad Distrital Francisco José de Caldas, sede administrativa, Carrera $7 .{ }^{\text {a }}$ n. ${ }^{\circ}$ 40B-53, piso 4, Bogotá, Colombia. Correo electrónico: molsancheza@correo.udistrital.edu.co

Recibido: enero 20 del $2018 \quad$ Aprobado: mayo 22 del $2018 \quad$ Disponible en línea: septiembre 1 del 2018
Cómo citar este artículo: M. L. Sánchez-Arévalo, L. F. Cruz-Hueso y R. Ferro-Escobar, "Modelo de aproximación al comportamiento
de la deserción voluntaria universitaria en pregrados de Ingeniería periodo 2015-2018", Revista Ingeniería Solidaria, vol. 14, no. 26,
2018. doi: https://doi.org/10.16925/in.v14i26.2452

\section{Resumen}

Introducción: el presente artículo es producto de investigación del "Modelo de aproximación al comportamiento de la deserción voluntaria universitaria en pregrados de Ingeniería", realizado durante el periodo 2015-2018 en la Universidad Distrital Francisco José de Caldas.

Problema: según diversos estudios preliminares, la educación universitaria a nivel mundial posee carencias y problemáticas que generan altos niveles de deserción.

Objetivo: dar a conocer los niveles de deserción estudiantil y su proyección en estas carreras a nivel nacional e internacional.

Metodología: para dar una visión a nivel Colombia, se generan reportes estadísticos de la problemática apoyados por la herramienta del SPADIES ${ }^{1}$. A nivel mundial, se basa en los datos generados por el Banco Mundial y la Organización de las Naciones Unidas para la Educación, la Ciencia y la Cultura (Unesco).

Conclusión: comprender la educación como un ámbito continuamente expuesto al cambio puede generar estrategias de mitigación de falencias y garantizar la permanencia de los estudiantes.

Resultados: la importancia del seguimiento de los factores fortalece el análisis estadístico midiendo y cuantificando los niveles de incorporación y de deserción.

Limitaciones: la carencia de información suministrada por la Universidad Distrital dificulta su respectivo análisis. Originalidad: se presenta un análisis de deserción de los estudiantes de Ingeniería a nivel mundial y se plantea la creación de una base compacta para la Universidad Distrital.

Palabras clave: deserción estudiantil, deserción en ingeniería, tasas de deserción, variables de deserción.

1 SPADIES: Sistema para la Prevención y Análisis de la Deserción en las Instituciones de Educación Superior [19]. 


\title{
Behavior Approach Model of Voluntary University Desertion in Undergraduate Programs in Engineering, Period 2015-2018
}

\begin{abstract} of Engineering" conducted during 2015-2017 at the Universidad Distrital Francisco José de Caldas. problems that cause high dropout levels.

Aim: To reveal student dropout levels and their impact on these programs nationally and internationally. by the World Bank and the United Nations Educational, Scientific and Cultural Organization (unEsco) were used. mitigate shortcomings and ensure the presence of students. quantifying enrollment and dropout levels.

Limitations: The little information provided by the Universidad Distrital hinders its analysis. base for the Universidad Distrital is proposed.

Keywords: student dropout, engineering dropout, dropout rates, dropout variables.

\section{Modelo de aproximação ao comportamento da investigação voluntária universitária nos programas de graduação em Engenharia, periodo 2015-2018}

Introduction: This article is a research product of "Model Approach to University Dropout Behavior in Schools

Problem: According to several preliminary studies, university education worldwide has deficiencies and

Methods: To provide a national outlook, statistical reports of the problem were produced using the Higher Education Institution Dropout Prevention and Analysis System (SPADIES) tool. For a global view, data gathered

Conclusion: Understanding education as a field continually exposed to change may give rise to strategies to

Results: The importance of monitoring the factors strengthens the statistical analysis by measuring and

Originality: An engineering student dropout analysis worldwide is presented and the creation of a compact

\section{Resumo}

Introdução: este artigo surgiu da pesquisa do "Modelo de abordagem ao comportamento da evasão no ensino superior nas Faculdades de Engenharia", realizado no período de 2015-2017 na Universidad Distrital Francisco José de Caldas.

Problema: de acordo com vários estudos preliminares, o ensino superior em todo o mundo tem deficiências e problemas que geram altos níveis de evasão.

Objetivo: divulgar os níveis de evasão no ensino superior e sua projeção nessas carreiras nos níveis nacional e internacional.

Metodologia: para dar uma visão da perspectiva na Colômbia, são gerados relatórios estatísticos do problema utilizando o Sistema de Prevenção e Análise da Deserção em Instituições de Ensino Superior (SPADIES). Mundialmente, baseia-se em dados gerados pelo Banco Mundial e pela Organização das Nações Unidas para a Educação, a Ciência e a Cultura (UNESCO).

Conclusão: compreender a educação como um campo continuamente exposto à mudança pode gerar estratégias para mitigar as deficiências e garantir a permanência dos estudantes.

Resultados: 0 acompanhamento dos fatores reforça a análise estatística, medindo e quantificando os níveis de incorporação e deserção.

Limitações: a falta de informação fornecida pela Universidad Distrital dificulta a análise.

Originalidade: apresenta-se uma análise da evasão dos estudantes de Engenharia em todo 0 mundo e propõe-se a criação de uma base compacta para a Universidad Distrital.

Palavras-chave: evasão no ensino superior, evasão na Engenharia, taxas de evasão, variáveis de evasão. 


\section{Introducción}

La deserción o interrupción académica puede ser voluntaria o forzosa, y se presenta con un cambio de carrera dentro de la misma institución, con un cambio de universidad en el mismo u otro proyecto curricular y con la salida del sistema de educación superior, como lo registra la Universidad Pedagógica Nacional [1].

A su vez, de acuerdo con el Ministerio de Educación Nacional [2], el fenómeno de la deserción obedece a causas de orden familiar, personal, cultural o socioeconómico, y es uno de los problemas que hoy deben enfrentar el Gobierno y las Instituciones de Educación Superior, con efectos en áreas económicas, laborales, emocionales y sociales en las que intervienen el estudiante, la familia, la universidad y el país, según Meléndez [3].

La presente investigación está motivada por conocer el comportamiento de la deserción universitaria en programas de pregrado de Ingeniería, por tanto se centra en tomar una universidad colombiana como caso de estudio y determinar los factores principales por los cuales los estudiantes desertan. Para ello, se empleó una metodología de recolección de datos a través de un formulario de retiro, generando conclusiones para el caso particular. Posterior a ello, se realiza la comparación de las Instituciones de Educación Superior de orden oficial ${ }^{2}$ que imparten carreras de pregrado de Ingeniería, y se concluye con una visión global de la deserción en Ingeniería analizando las estadísticas de varios países.

\subsection{Investigaciones preliminares}

Algunas investigaciones, como la de Corengia et al. [4], evidencian el interés en detectar de manera temprana, y con base en el perfil cognitivo del individuo $^{3}$, la vulnerabilidad a sufrir fracasos académicos y una posterior deserción. Esto se toma como un instrumento para promover estrategias de asesoramiento y formación personalizada desde el proceso de admisión, siendo favorable para todas las Instituciones de Educación Superior que desean diseñar y aplicar políticas propias para lograr la disminución de las tasas de deserción [4].

Universidades del Estado (públicas).

A través de aptitudes educativas
La deserción estudiantil es un campo amplio, y cada una de las variables identificadas en el proceso tiene relación con un enfoque específico. Diversos autores han tratado la problemática desde diversos ámbitos; la tabla 1 muestra algunos de ellos y las características de estudio en temas de deserción académica. Así, se han logrado aportes para el reconocimiento y tratamiento de variables, permitiendo a las universidades crear e implementar estrategias en sus planes de acción para evitar el aumento de la tasa de deserción en relación desproporcionada con el nivel de ingreso a los proyectos curriculares.

Es así como el desarrollo de la educación se convierte en un tema primordial en todos los países, lo que permite reconocerla como una de las variables más importantes en el desarrollo social y económico. En la historia del mundo, se han observado diferentes brechas creadas en los procesos de evolución, con impacto en la oportunidad de desarrollo en los ámbitos estructurales, entre los que se incluyen las falencias a nivel educativo, evidenciadas en la posibilidad de capacitar de manera adecuada a cada uno de los jóvenes que deciden incorporarse de manera activa en la educación.

Las tendencias actuales y los nuevos desafíos que enfrenta la educación superior implican la necesidad de replantear su papel y su misión y de identificar nuevas prioridades para el futuro próximo, tal como lo afirma la Unesco [5]. La contextualización de la problemática se centra en identificar el conjunto de entes externos que pueden llegar a afectar de manera directa e indirecta el proceso educativo de los jóvenes en el mundo. Para la Unesco [6], si bien es claro que para ingresar a la educación superior se requiere más capital económico que el invertido en la escolaridad secundaria, cabe recalcar que el económico no es el único factor que genera deserción en el camino universitario.

Autores manifiestan que entre los factores más influyentes de la deserción universitaria se identifican: el estado socioeconómico familiar y el rendimiento académico, temática de importante abordaje dentro de la Universidad Distrital. Por eso, investigaciones como la de Varguese [7] y Rossi [8] identifican las variables que afectan el rendimiento académico de los estudiantes a tiempo completo, y se han venido implementando con mayor intensidad en diferentes partes del mundo, buscando crear planteamientos y propuestas de mejora que garanticen una educación superior de calidad y que le ofrezcan a cada uno de los países un capital humano más 
potencializado y activo. Algunos de los desafíos a los que están expuestos los procesos de evolución y cambio de la educación los describe la Unesco [5] $\mathrm{y}$ se presentan en la figura 1.
1.1.1 Relaciones con el Estado y la sociedad en general: el desarrollo de las entidades educativas en el mundo es un proceso de continuo cambio, en el que se debe buscar la libertad académica y la autonomía institucional.

Tabla 1. Autores y características de sus estudios en temas de deserción académica.

\begin{tabular}{|c|c|c|c|}
\hline Ámbito & Autores & Año & Características \\
\hline \multirow{4}{*}{ Biológico } & Fishbean y Ajzen & 1975 & \multirow{4}{*}{$\begin{array}{l}\text { Atributos y rasgos de personalidad del estudiante sin tener } \\
\text { presente las condiciones institucionales. }\end{array}$} \\
\hline & Attinasi & 1986 & \\
\hline & Ethington & 1990 & \\
\hline & Bean y Eaton & 2001 & \\
\hline Sociológico & Spady & 1970 & $\begin{array}{l}\text { Identificación de factores externos asociados a la institu- } \\
\text { ción y a la familia. }\end{array}$ \\
\hline \multirow{5}{*}{ Organizacional } & Kammens & 1971 & \multirow{5}{*}{ Deserción con base en las características de la institución. } \\
\hline & Braxton & 2000 & \\
\hline & Cabrera & 1990 & \\
\hline & Tillman & 2002 & \\
\hline & Himmel & 2002 & \\
\hline \multirow{4}{*}{ Económico } & Stampen y Hansen & 1990 & \multirow{4}{*}{$\begin{array}{l}\text { Identificación de variables costo/beneficio y focalización } \\
\text { de los subsidios. }\end{array}$} \\
\hline & Cabrera, Nora y Castañeda & 1992 & \\
\hline & St Jhon, Paulsen y Starkey & 1996 & \\
\hline & Porto et al. & 2001 & \\
\hline $\begin{array}{l}\text { Modelo } \\
\text { interaccionista }\end{array}$ & $\begin{array}{l}\text { Vincent Tinto (autor repre- } \\
\text { sentativo) }\end{array}$ & 1975 & $\begin{array}{l}\text { Integración y adaptación del estudiante son prioridades } \\
\text { en el desarrollo de su proceso, dicha interacción posibilita } \\
\text { su desarrollo profesional y académico. }\end{array}$ \\
\hline
\end{tabular}

Fuente: adaptado por autores

\section{Relaciones con el Estado y la sociedad en general}

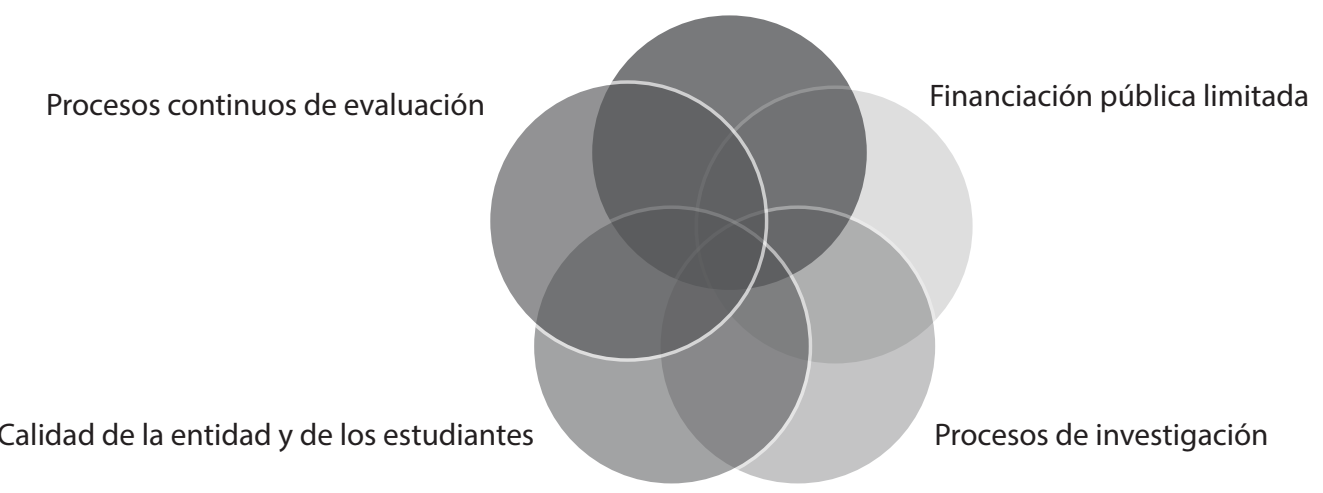

Figura 1. Desafíos de la educación.

Fuente: elaboración propia con base en Unesco [5] 
1.1.2 Financiación pública limitada: la financiación o el apoyo que brinda el Estado a muchas de las Instituciones de Educación Superior en el mundo a veces no son suficientes, lo cual ha generado que se busque una fuente de financiación propia. Pero a esta problemática se suma que algunas universidades tienen un uso inadecuado de recursos humanos y físicos, generando pérdidas en capital.

1.1.3 Procesos de investigación: las Instituciones de Educación Superior tienen que generar una búsqueda continua para mantener un enlace entre las diferentes áreas que facilite su proceso de desarrollo y evolución.

1.1.4 Calidad de la institución y de los estudiantes: buscar un continuo mejoramiento ofreciendo procesos y programas de calidad motiva y ayuda a los estudiantes activos en el proceso educativo; en pocas palabras, se debe generar un proceso de acompañamiento.

1.1.5 Proceso de evaluación: cada uno de los miembros de la comunidad educativa debería tener un proceso activo dentro del desarrollo y la evolución del ámbito educativo, generando integración y aportes oportunos en procesos de mejora.

Para Hazelkorn [9], "la educación superior y en especial la investigación académica se ha convertido en el foco del interés político y geopolítico en todo el mundo como un motor de la economía y el crecimiento". De esta manera, se confirma que la educación puede garantizar una ventaja competitiva y aportar a un proceso educativo evolutivo mundial.

\section{Contextualización}

\subsection{Deserción estudiantil universitaria}

Debido al creciente interés en investigaciones acerca de las variables que influyen en el desarrollo de un país, la educación se ha posicionado como un elemento de vital importancia en la sociedad. La Organización Panamericana de la Salud (ops) [10], en su informe del 2012, define la educación y la salud como los ejes fundamentales de desarrollo que afectan positiva o negativamente las condiciones sociales, económicas y culturales de los países. El aumento de los índices educativos se asocia al mejoramiento de la salud y al incremento de la productividad, la movilidad social, la reducción de la pobreza y la construcción de ciudadanía; por esto, los países se han enfocado en políticas para mejorar la calidad de la educación y a su vez mitigar la deserción académica en todos los niveles de formación.

Según Patiño-Garzón y Cardona-Pérez [11], la deserción es un fenómeno complejo y de múltiples impactos negativos tanto para el estudiante, como para la propia universidad, y por ende para la región y la sociedad [1]. A fin de entrar a fondo en esta problemática, se revisan las causas y los factores que intervienen. Ejemplo de ello es el estudio de Sánchez et al. [12], realizado en la Universidad Surcolombiana, el cual indica los siguientes como factores principales de la deserción universitaria:

- Factores personales: incluyen motivos psicológicos (motivacionales, emocionales, desadaptación e insatisfacción de expectativas), motivos sociológicos (influencias familiares, amigos, condiscípulos, vecinos) y otros motivos no clasificados (edad, salud, fallecimiento, entre otros).

- Factores académicos: comprenden problemas cognitivos (bajo rendimiento académico, repitencia, ausencia de disciplina y métodos incorrectos de estudio) y deficiencias universitarias (insatisfacción académica generada por falta de espacios pedagógicos adecuados para el estudio, falta de orientación profesional y ausencia de aptitud académica).

- Factores socioeconómicos: generados por bajos ingresos familiares, desempleo, falta de apoyo familiar e incompatibilidad de horarios entre trabajo y estudio.

- Factores institucionales: causados por cambio de institución, deficiencia administrativa, influencia negativa de personal y docentes de la institución, programas académicos obsoletos y rígidos, y baja calidad educativa.

Vincent Tinto, como lo cita Carvajal [13], propone un modelo de causas de deserción que integra factores y etapas que atraviesan los universitarios, encontrando: atributos familiares e individuales, educación superior anterior, métodos de enseñanza, apoyo institucional, situación económica, eventos familiares, estado de salud e integración académica y social. Todo esto influye directamente en los objetivos personales e institucionales, siendo ámbitos decisivos en la decisión de retiro o permanencia del proyecto curricular o de la universidad 
a la que pertenece el estudiante. El modelo se presenta en la figura 2 .

En el inicio de la vida universitaria, se genera algún grado de estrés relacionado con los nuevos retos del estudiante; así, todos los individuos en esta etapa atraviesan por un periodo de adaptación que puede presentarse como un ajuste exitoso o como la imposibilidad de acoplarse, generando la deserción por dificultades académicas o por factores personales y sociales, de acuerdo con el estudio del Icfes y la Universidad Nacional [14].

Un estudio realizado en la Universidad del Magdalena, en Colombia, presenta casos de depresión entre los estudiantes universitarios, por lo cual se tiene la urgente necesidad de que la institución implemente acciones de prevención, tanto de investigación como de intervención, a través del Departamento de Bienestar Universitario y el programa de Psicología, a fin de evitar comportamientos disfuncionales o desadaptativos, así como conductas que pueden ir desde las fallas reiteradas $y$ las deserciones hasta el intento o el acto suicida, según señalan Ferrel et al. [15].

\subsection{Deserción estudiantil universitaria en Colombia}

En Colombia, en el 2003, se empezaron a desarrollar investigaciones acerca de esta problemática basadas en la revisión profunda de literatura sobre deserción estudiantil, con el objetivo de identificar los factores y las variables que permiten explicar empíricamente sus causas.

Dicha aproximación teórica permitió que el estudio realizado por el Ministerio de Educación Nacional entre el 2005 y el 2006, mediante la contratación de la Universidad de los Andes para su ejecución y la interventoría técnica de la Universidad de Antioquia, sirviera para que diferentes Instituciones de Educación Superior conocieran dicho problema, los ciclos que presenta, los modelos de duración y detectar el riesgo de deserción en cada estudiante. Lo anterior, junto con el seguimiento institucional, se consolidó en la herramienta de medición sPADIES (Sistema para la Prevención y Análisis de la Deserción en las Instituciones de Educación Superior; [16]), que permite a cada institución identificar y clasificar a los estudiantes desertores.

El Ministerio de Educación Nacional, en el 2009, dictaminó algunas conclusiones frente a esta problemática, consignadas en el estudio de Carvajal $[13$, p. 4], en el que se indica que la revolución educativa frente al seguimiento y la atención estudiantil centró sus esfuerzos en "condiciones individuales, socioeconómicas, institucionales y financieras, pues son estas las que lo impulsan a mantenerse o a abandonar sus estudios, a partir de esta política la

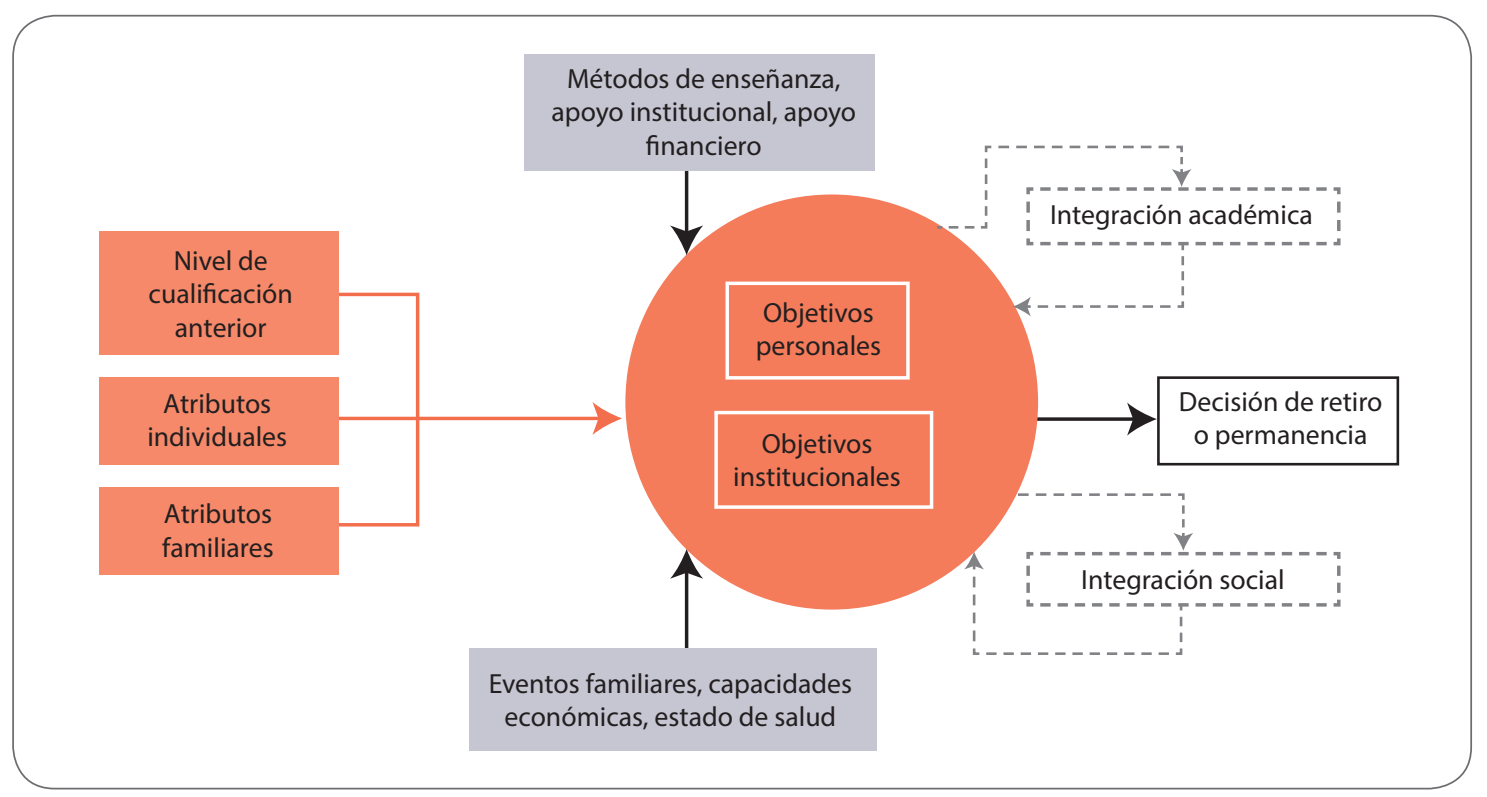

Figura 2. Modelo de deserción estudiantil en la educación superior.

Fuente: Carvajal [13] 
educación superior colombiana cuenta con directrices para fortalecer la permanencia y la graduación estudiantil".

Según las entidades nacionales reguladoras de la educación, la deserción es un problema bastante serio ya que el $52 \%$ de los estudiantes colombianos que empiezan una carrera universitaria no la concluyen, es decir que de cada dos estudiantes matriculados en un programa de pregrado, solo uno culmina su carrera, como lo describe Carvajal [13].

En noviembre del 2010, el Gobierno colombiano, junto a representantes de diferentes Instituciones de Educación Superior, suscribió el Acuerdo para Disminuir la Deserción en Educación Superior, siendo un gran aporte a esta problemática. Según Quintero [17, p. 77], con este acuerdo se busca fortalecer "la participación de diversos actores e instituciones que llevan al mejoramiento de la calidad y de los procesos de formación académica, y a la reducción de los índices de deserción mediante la promoción de los procesos de acceso y permanencia al sistema educativo".

El esfuerzo evidente del sistema universitario colombiano por incrementar la cobertura de la educación superior ha permitido el ingreso de un mayor número de universitarios. En la figura 3, se muestra la relación de los estudiantes matriculados en proyectos curriculares de pregrado frente a la población entre 17 y 21 años en el periodo 20052015 en Colombia, de acuerdo con lo registrado en el Sistema Nacional de Información de Educación Superior (sNies) [18], que mide el aumento de la participación de jóvenes y adultos que están efectivamente cursando un programa de educación superior.

Con lo anterior, se pensaría que se está generando un buen panorama para aumentar y garantizar la cantidad de profesionales que gozan de la educación superior en Colombia, pero se debe tener en cuenta que ha sido poco lo que se ha hecho para reducir las tasas de deserción, tal como lo registran Malagón et al. [19, p. 18]: "Mientras se intenta incrementar el ingreso, se mantienen altas las cifras de retiro del sistema, lo cual va en detrimento del número de jóvenes profesionales formados".

Los índices de deserción universitaria en el país para el periodo 2005-2015, según el sNies [18], se evidencian en la figura 4 , en la que se concluye que los mayores índices se presentaron en los años 2005 y 2010 , con $13,49 \%$ y $12,9 \%$, respectivamente.

Según los análisis realizados en el spadies, se han identificado los primeros cuatro semestres como el periodo en el que se concentra el 75\% del total de desertores. Los principales factores

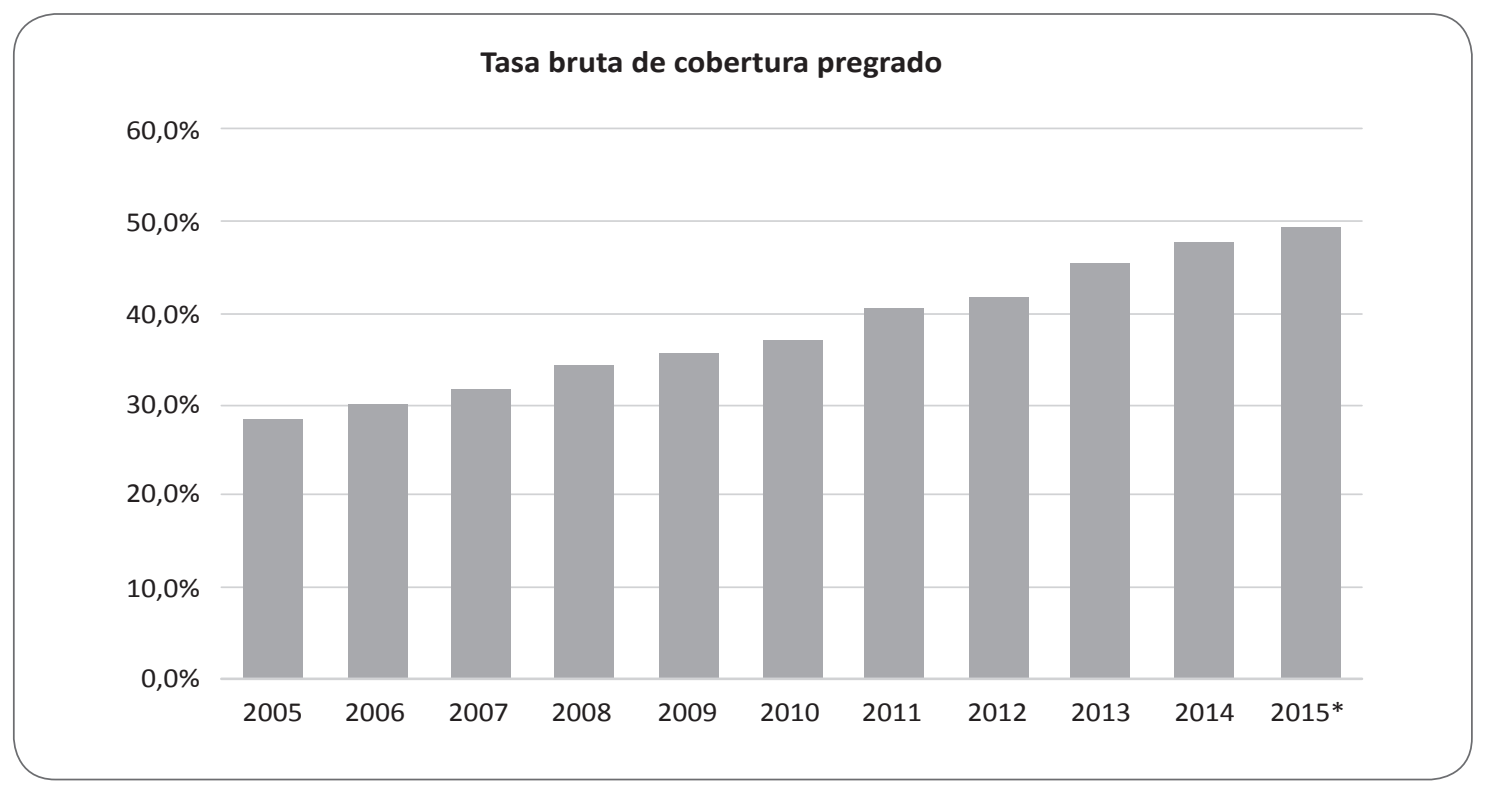

Figura 3. Tasa bruta de cobertura de educación superior en Colombia (2005-2015).

${ }^{\star}$ El dato que se toma de matrícula es el del primer semestre siempre. Para esta variable no se pueden sumar los dos periodos. Fuente: adaptado por autores con base en SNIEs [18] 


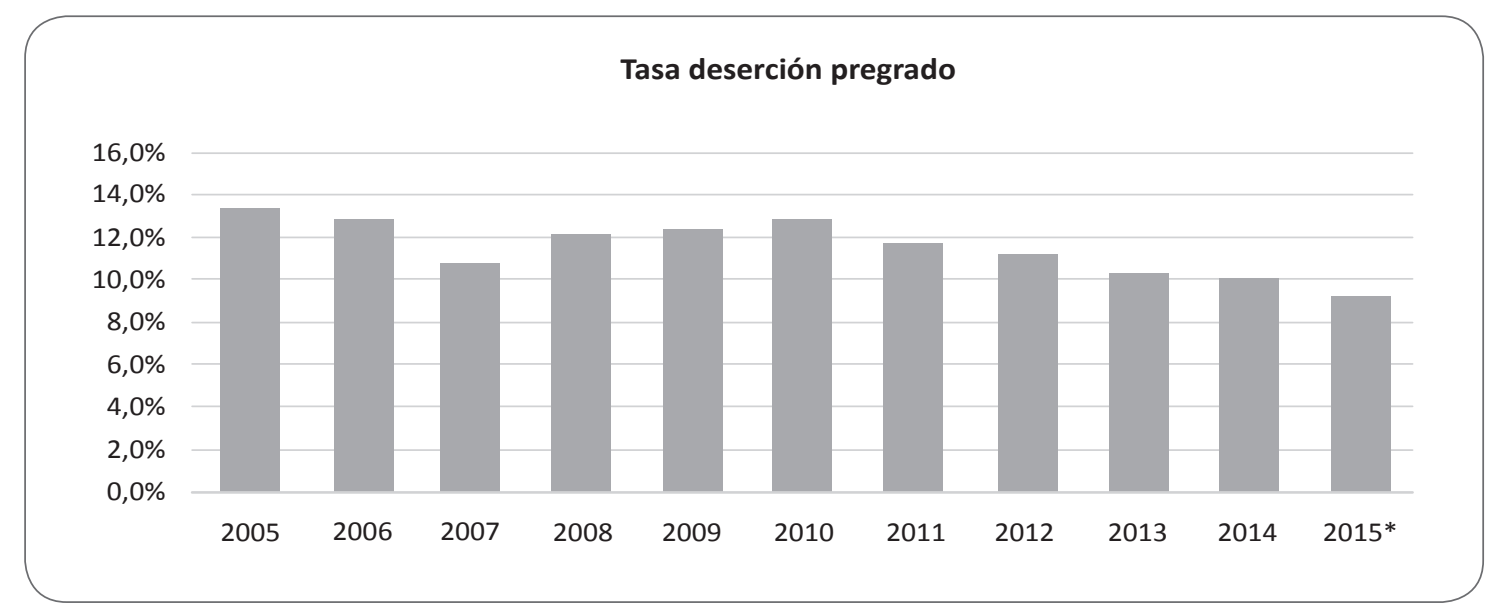

Figura 4. Tasas de deserción por cohorte a nivel Colombia (2006 a 2014)

Fuente: adaptado por autores con base en sNies [18]

asociados a este fenómeno, en el caso colombiano, están vinculados con las bajas competencias académicas de entrada, las dificultades económicas de los estudiantes y los aspectos relacionados con la orientación socioocupacional y la adaptación al ambiente universitario. La figura 5 permite identificar el nivel de deserción de las carreras profesionales universitarias en Colombia según la matrícula cursada, y se muestra que la mayoría de estudiantes que desertan lo hacen en los primeros cuatro semestres académicos.

Con lo anterior, se sustenta la necesidad de revisar y plantear estudios propios que incurran en hallar las variables que en realidad están causando este flagelo, a fin de combatirlo con todos sus actores en propuestas de políticas universitarias.

\section{Metodología}

El desarrollo de la presente investigación se divide en tres fases con un abordaje cuantitativo. Para ello, se tendrá en cuenta el tratamiento y el análisis de los datos presentados según el nivel de especificidad evaluado.

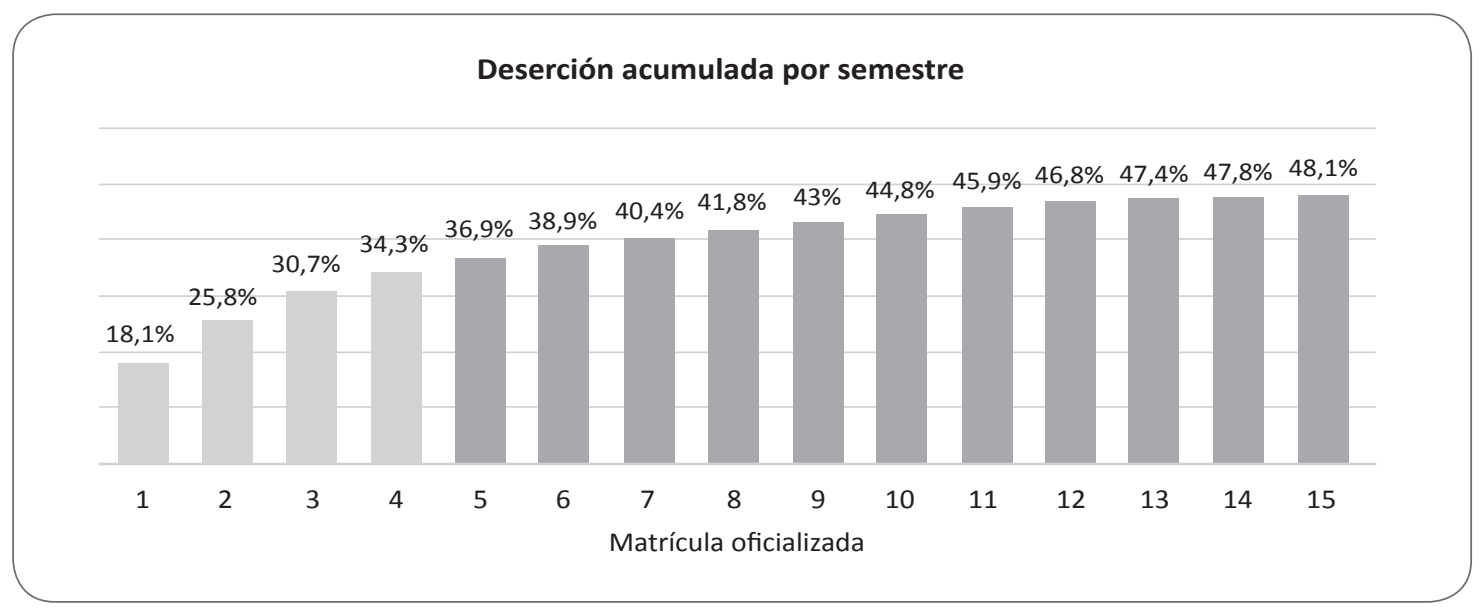

Figura 5. Comportamiento de deserción en carreras universitarias en Colombia según el número de semestres o matrículas oficializadas.

Fuente: adaptado por autores con base en SPADIEs [20] 
1. Estudio de caso de la deserción de carreras de pregrado en la Facultad de Ingeniería de la Universidad Distrital Francisco José de Caldas:

a) Estadísticas de deserción general de la Facultad de Ingeniería de pregrado por cohorte de 2009-II a 2017-I, en las cuales se presentan las cohortes con mayor deserción acumulada encontrada. Un ejemplo de ello es que un estudiante al ingresar en el 2010-I deserta en el 2013-III, el dato de su deserción se incluirá en el 2010-I, por lo que se toma como elemento clasificador el semestre en el cual el estudiante era primíparo. Se tomaron desde el 2009-II, dado que hubo un cambio curricular en los pregrados de la facultad por la implementación de los créditos académicos y nuevas mallas curriculares.

b) Los datos estructurados y clasificados de las estadísticas del ítem anterior permitieron que se encontrara la tendencia del comportamiento de la deserción en función del semestre de ingreso, creando una ecuación que caracteriza de manera matemática esta problemática en la facultad, con ayuda de IBM spss Statistics y Excel.

c) Estadísticas de deserción por cohorte de 2009-II a 2017-I en las carreras de Ingeniería de pregrado de dicha facultad, al tomar los datos de los reportes por cada cohorte, según el estado académico de cada estudiante y diferenciándolo según el proyecto curricular al que pertenecía, con el fin de ver la variación del comportamiento con la variable del proyecto curricular.

d) Para el tratamiento de la información que se recolectó mediante el formato de seguimiento a solicitudes de deserción, se inició por la definición de las variables a utilizar. Posterior a ello, se tomó cada una de las actas del Consejo de Facultad que referenciaba un caso de deserción desde el 2016-I de estudiantes bajo la modalidad de créditos. La información se presenta en las cohortes 2016-I, 2016-II y 2017-I, clasificada por género, proyecto curricular, motivo y semestre de deserción.

2. Estadísticas de deserción de carreras de pregrado de Ingeniería a nivel Colombia: a) Clasificación de las universidades a evaluar mediante el aplicativo del sNies [17]. Con la búsqueda realizada en el sistema SPADIEs 3.0, se evidencian 1.054 programas ofertados por las diferentes universidades en las áreas de Ingeniería, Arquitectura, Urbanismo y afines. Posterior a otros filtros como: (i) Carácter académico: universidad; (ii) Sector: oficial; (iii) Núcleo Básico del Conocimiento: ingeniería, se descartaron los programas que no fueran propios, obteniendo 31 universidades con dichas características.

b) Generación y análisis de reportes de la información suministrada por la herramienta SPADies 3.0, en la cual se halló la información de las 31 universidades seleccionadas en el ítem (a) de universidades oficiales que imparten carreras de pregrado de Ingeniería a nivel Colombia, clasificándolas por género y ubicando la deserción por cohorte de los periodos 2012-I a 2016-II para hacer análisis de la información obtenida.

3. Estadísticas de deserción de carreras de pregrado de Ingeniería a nivel mundial:

a) Generación y análisis de reportes de datos basado en carreras de pregrado de Ingeniería en universidades extranjeras, tomando como referencia los datos reportados por la Unesco y el Banco Mundial en el periodo 2010-2015: (a) Selección y tratamiento de la data de estudiantes que pertenecieron a un programa de Ingeniería y que culminaron con éxito su programa académico en América Latina y el Caribe; (b) Selección de la data de estudiantes de género femenino que pertenecieron a un programa de Ingeniería y que culminaron con éxito su programa académico en América Latina y el Caribe; (c) Selección de la data de estudiantes de género masculino que pertenecieron a un programa de Ingeniería y que culminaron con éxito su programa académico en América Latina y el Caribe; (d) Tratamiento y análisis de los niveles de deserción de las carreras de Ingeniería por cada uno de los países de América Latina y el Caribe tanto en género masculino como femenino y en su totalidad. 


\section{Resultados}

\subsection{Caracterización de la población desertora de la Facultad de Ingeniería de la Universidad Distrital Francisco José de Caldas}

El ingreso a la Universidad Distrital Francisco José de Caldas es uno de los retos más grandes para muchos estudiantes en la ciudad de Bogotá (Colombia), y aunque ingresar no es una tarea fácil, no es el principal problema que enfrentan. La deserción estudiantil en la Facultad de Ingeniería con el paso de los años ha ido incrementándose, lo que genera una alerta para la búsqueda de estrategias que puedan mitigar este ámbito.

Lo anterior indica de forma directa que no se está cumpliendo con los retos académicos y que no se están culminando con éxito las etapas del ciclo académico de los estudiantes de la facultad, poniendo en riesgo el sistema educativo nacional y la calidad de la institución, tal como lo señala Sánchez-Arévalo [21].

En la actualidad, la Facultad de Ingeniería de la Universidad Distrital cuenta con cinco proyectos curriculares de pregrado: Ingeniería Industrial, Ingeniería de Sistemas, Ingeniería Catastral y Geodesia, Ingeniería Eléctrica e Ingeniería Electrónica. Para el primer semestre del 2015, contaba con 5.535 estudiantes activos y una tasa de deserción promedio por cohorte de los últimos diez años (2005-2015) de 21,3\%, establecida a través de la relación del número de personas admitidas y el número de desertores de la facultad:

Tasa de deserción de cohorte $=$

Número de desertores cohorte

Número de admitido cohorte

En la figura 6, se observa la gravedad de la deserción y el aumento de las tasas de dicho comportamiento evaluado en estudiantes matriculados en el periodo 2009-II - 2017-I. Así, se concluye que la cohorte 2014-I presenta el mayor índice de deserción de manera general en los proyectos de pregrado de la Facultad de Ingeniería, con el $49,8 \%$

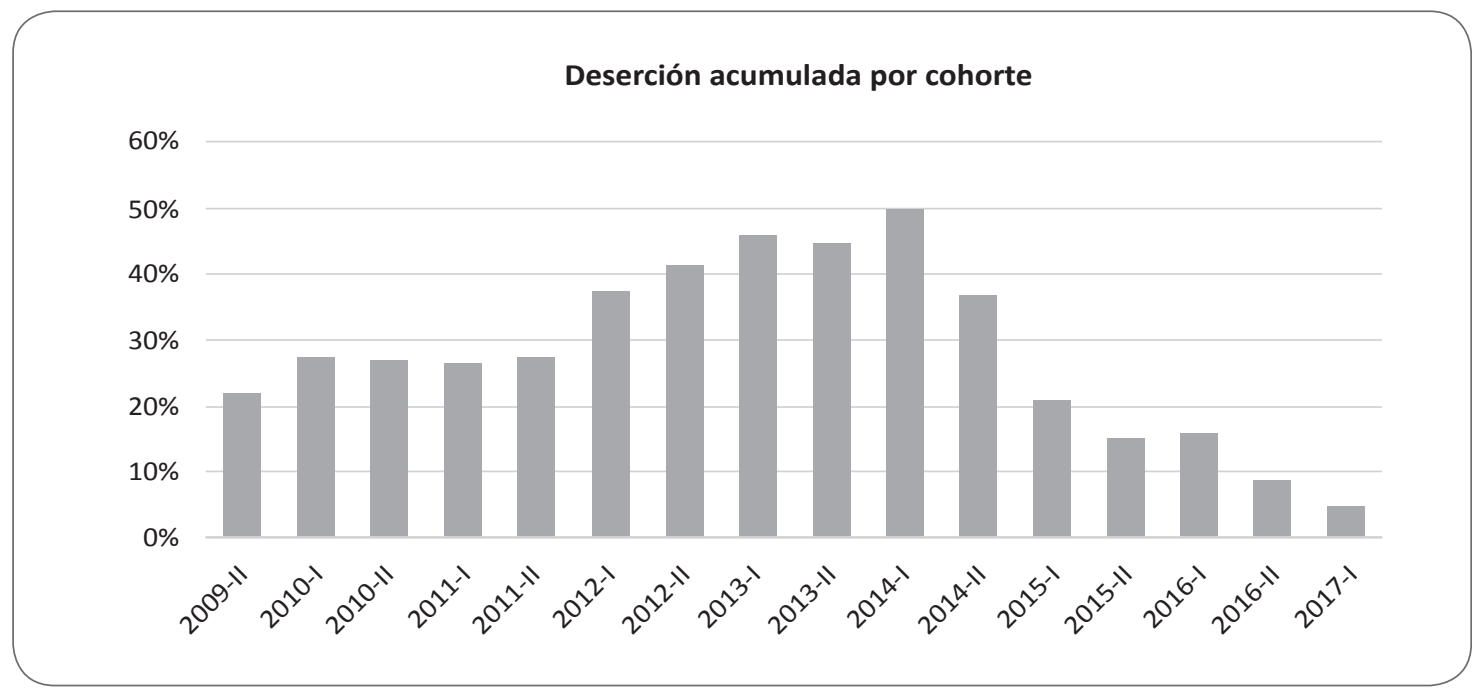

Figura 6. Tasas de deserción por cohorte de la Facultad de Ingeniería (2009-II a 2017-I).

Fuente: adaptado por autores con base en la Oficina Asesora de Sistemas (OAs) [22] de la Universidad Distrital Francisco José de Caldas 


\subsubsection{Tendencia del comportamiento de la deserción}

A fin de calcular la ecuación de tendencia de la deserción para la Facultad de Ingeniería, tomando los datos de la figura 6 y apoyados en la teoría, se utiliza el comportamiento de los estudiantes de quinto semestre hacia adelante, es decir, la cohorte 2015-I a la 2009-I, para lo cual se define una regresión polinómica de orden seis y con coeficiente de correlación $\left(\mathrm{R}^{2}\right)$ 0,9651:

$$
\begin{gathered}
\operatorname{Deserción}(x)=-0,0012(x)^{6}+0,0489(x)^{5}-0,8231(x)^{4}+ \\
6,8299(x)^{3}-27,969(x)^{2}+52,695(x)-8,8121
\end{gathered}
$$

En donde (x) es el número de la cohorte, siendo 2009-I X=1, 2010-I X=2, (...), 2015- $\mathrm{I}$ X=12.

Según el tratamiento de la información de la Oficina Asesora de Sistemas (OAS) de la Universidad Distrital Francisco José de Caldas, se obtuvieron los datos consignados en la tabla 2, en la que por cada proyecto curricular de pregrado de la Facultad de Ingeniería de la Universidad Distrital se relacionan las tasas de deserción por cohorte de estudiantes bajo la modalidad de créditos, que permite enlistar algunas conclusiones.

El proyecto curricular que más desertores tuvo en el lapso comprendido entre el 2009-II y el 2017-I fue Ingeniería Electrónica, con un porcentaje total de $63,2 \%$ de los estudiantes que ingresaron en la cohorte 2014-I. El proyecto curricular que mayor cohorte de deserción tuvo fue Ingeniería Electrónica, ya que de las dieciséis cohortes presentó cinco. La carrera que ocupa el segundo lugar en porcentaje de deserción es Ingeniería de Sistemas, seguida por Ingeniería Catastral y Geodesia e Ingeniería Eléctrica. A su vez, el proyecto curricular con menor porcentaje de deserción en este lapso fue Ingeniería Industrial, con valores comprendidos entre el 2,2\% y el $41,5 \%$.

\subsubsection{Tratamiento de información mediante formato de seguimiento a solicitudes de deserción}

En el primer trimestre del 2016, la Secretaría Académica de la Facultad de Ingeniería de la Universidad Distrital realizó e implementó el Formato para Retiro Voluntario y Definitivo Facultad de

Tabla 2. Tasa de desertores por cohorte académica, discriminado por proyecto curricular según el sistema académico de la oAS

\begin{tabular}{|c|c|c|c|c|c|c|}
\hline Cohorte & Electrónica & Eléctrica & Industrial & Sistemas & Catastral & Máximo \\
\hline 2009-II & $27,0 \%$ & $24,4 \%$ & $14,3 \%$ & $15,6 \%$ & $29,4 \%$ & $29,4 \%$ \\
\hline 2010-I & $23,1 \%$ & $32,9 \%$ & $28,5 \%$ & $24,6 \%$ & $29,7 \%$ & $32,9 \%$ \\
\hline 2010-II & $24,5 \%$ & $26,8 \%$ & $24,6 \%$ & $20,3 \%$ & $38,1 \%$ & $38,1 \%$ \\
\hline 2011-I & $33,0 \%$ & $16,9 \%$ & $24,0 \%$ & $27,7 \%$ & $27,5 \%$ & $33,0 \%$ \\
\hline 2011-II & $48,3 \%$ & $24,0 \%$ & $17,1 \%$ & $20,8 \%$ & $20,7 \%$ & $48,3 \%$ \\
\hline 2012-I & $46,0 \%$ & $31,9 \%$ & $29,4 \%$ & $36,1 \%$ & $42,4 \%$ & $46,0 \%$ \\
\hline 2012-II & $47,9 \%$ & $44,1 \%$ & $31,1 \%$ & $50,8 \%$ & $32,8 \%$ & $50,8 \%$ \\
\hline 2013-I & $36,6 \%$ & $56,6 \%$ & $34,2 \%$ & $55,2 \%$ & $45,1 \%$ & $56,6 \%$ \\
\hline 2013-II & $47,1 \%$ & $48,1 \%$ & $32,3 \%$ & $51,8 \%$ & $43,1 \%$ & $51,8 \%$ \\
\hline 2014-I & $63,2 \%$ & $54,1 \%$ & $41,5 \%$ & $47,7 \%$ & $42,4 \%$ & $63,2 \%$ \\
\hline 2014-II & $43,7 \%$ & $36,4 \%$ & $29,5 \%$ & $56,1 \%$ & $18,1 \%$ & $56,1 \%$ \\
\hline 2015-I & $14,6 \%$ & $28,0 \%$ & $14,4 \%$ & $25,2 \%$ & $22,5 \%$ & $28,0 \%$ \\
\hline 2015-II & $13,3 \%$ & $15,0 \%$ & $10,1 \%$ & $16,7 \%$ & $20,9 \%$ & $20,9 \%$ \\
\hline 2016-I & $18,4 \%$ & $14,5 \%$ & $13,6 \%$ & $15,9 \%$ & $16,1 \%$ & $18,4 \%$ \\
\hline 2016-II & $8,7 \%$ & $6,1 \%$ & $5,4 \%$ & $9,0 \%$ & $13,8 \%$ & $13,8 \%$ \\
\hline 2017-I & $5,4 \%$ & $2,4 \%$ & $2,2 \%$ & $8,4 \%$ & $5,8 \%$ & $8,4 \%$ \\
\hline
\end{tabular}
entre 2009-II y 2017-I.

Fuente: elaboración propia con base en oAs [22] 
Ingeniería GA-FR-FI-01, junto con el Instructivo para la Solicitud de Retiro Voluntario Definitivo Facultad de Ingeniería. En este formato, el estudiante explica el motivo que lo llevó a tomar la decisión de abandonar su cupo universitario.

El formato GA-FR-FI-01 busca hacer un seguimiento oportuno de los casos que se están presentando para generar una solución alternativa y disminuir el índice de deserción en la facultad. En este artículo, se presentan los factores predominantes en la deserción de la facultad y en qué periodos académicos se ha generado un mayor número de desertores, así como un pronóstico que permite la creación de estrategias efectivas.

Para alimentar la base de datos que permitiría el análisis de los factores de deserción, se seleccionaron los estudiantes que ingresaron en el periodo comprendido entre el 2009-II y el 2017-I, correspondientes a los proyectos curriculares de Ingeniería Industrial, Ingeniería de Sistemas, Ingeniería Catastral y Geodesia, Ingeniería Eléctrica e Ingeniería Electrónica, cobijados bajo el sistema de créditos implementado por la Universidad Distrital Francisco José de Caldas por Resolución 035 de septiembre 19 del 2006. La base de datos consultada para el análisis proviene de la oAs, que cuenta con un registro de los estudiantes desertores por periodo o cohorte académica, teniendo las variables consignadas en la tabla 3 .

Tabla 3. Variables de registro de estudiantes desertores por periodo o cohorte académica en reporte de la oAs.

\begin{tabular}{ll}
\hline \multicolumn{1}{c}{ Variable } & \multicolumn{1}{c}{ Descripción } \\
\hline $\begin{array}{l}\text { Proyecto } \\
\text { curricular }\end{array}$ & $\begin{array}{l}\text { Ingeniería a la cual pertenece el alumno } \\
\text { desertor }\end{array}$ \\
Género & $\begin{array}{l}\text { Femenino/Masculino } \\
\text { Cohorte }\end{array}$ \\
Estado & $\begin{array}{l}\text { Estado en el cual se encuentra el estu- } \\
\text { diante en la universidad }\end{array}$ \\
\hline
\end{tabular}

Fuente: elaboración propia

En vista de la carencia de información, se complementa con los datos recolectados del Formato para Retiro Voluntario y Definitivo Facultad de Ingeniería, el cual permite identificar las variables descritas en la tabla 3. Dichas variables brindan la información cuantitativa oportuna para el estudio del caso, facilitando el análisis de los resultados y futuros planteamientos de propuestas de mejora que buscan mitigar los niveles de deserción.

Tabla 4. Variables de registro estudiantes desertores por periodo o cohorte académica.

\begin{tabular}{ll}
\hline \multicolumn{1}{c}{ Variable } & \multicolumn{1}{c}{ Descripción } \\
\hline Género & Femenino - Masculino \\
Cohorte de ingreso & $\begin{array}{l}\text { Periodo en el que ingresó el } \\
\text { estudiante }\end{array}$ \\
Periodo solicitud & $\begin{array}{l}\text { Periodo en el cual radicó el } \\
\text { fermato ante la universidad } \\
\text { Causal de retiro }\end{array}$ \\
& $\begin{array}{l}\text { Motivo que manifiesta el estudiante } \\
\text { para radicar su retiro voluntario }\end{array}$ \\
\hline
\end{tabular}

Fuente: elaboración propia con base en información de la Secretaría Académica Facultad de Ingeniería

Finalmente, se presentan estadísticas y análisis de la deserción en la Facultad de Ingeniería de estudiantes de pregrado que radicaron su solicitud en los semestres 2016-I, 2016-II y 2017-I, clasificándolos por proyecto curricular, motivo de retiro, sexo y número de semestres oficializados. Los análisis fueron los siguientes:

\section{Causales de deserción periodo 2016-I}

En la figura 7, se muestra la cantidad de estudiantes de género masculino por causal de deserción en el periodo académico 2016-I, obteniendo como motivo principal Económico, con un total de catorce estudiantes (en una población total de 69 estudiantes), cuyo valor máximo está en el proyecto curricular de Ingeniería de Sistemas. Así mismo, se evidencia que los factores próximos de incidencia de deserción son: Académico y Cambio de carrera, con trece estudiantes cada uno. Por último, se puede concluir que la tasa de deserción total de hombres en el periodo 2016-I corresponde al 83\% de la población total desertora de ese semestre.

En la figura 8, se presenta la causal de deserción de estudiantes de género femenino en el periodo académico 2016-I, analizando que el motivo Cambio de carrera es el que mayor número de estudiantes presenta en el registro de deserción (cinco estudiantes en una población total de catorce estudiantes). La siguiente causal con mayor número de estudiantes es Cambio de domicilio, seguido por los 


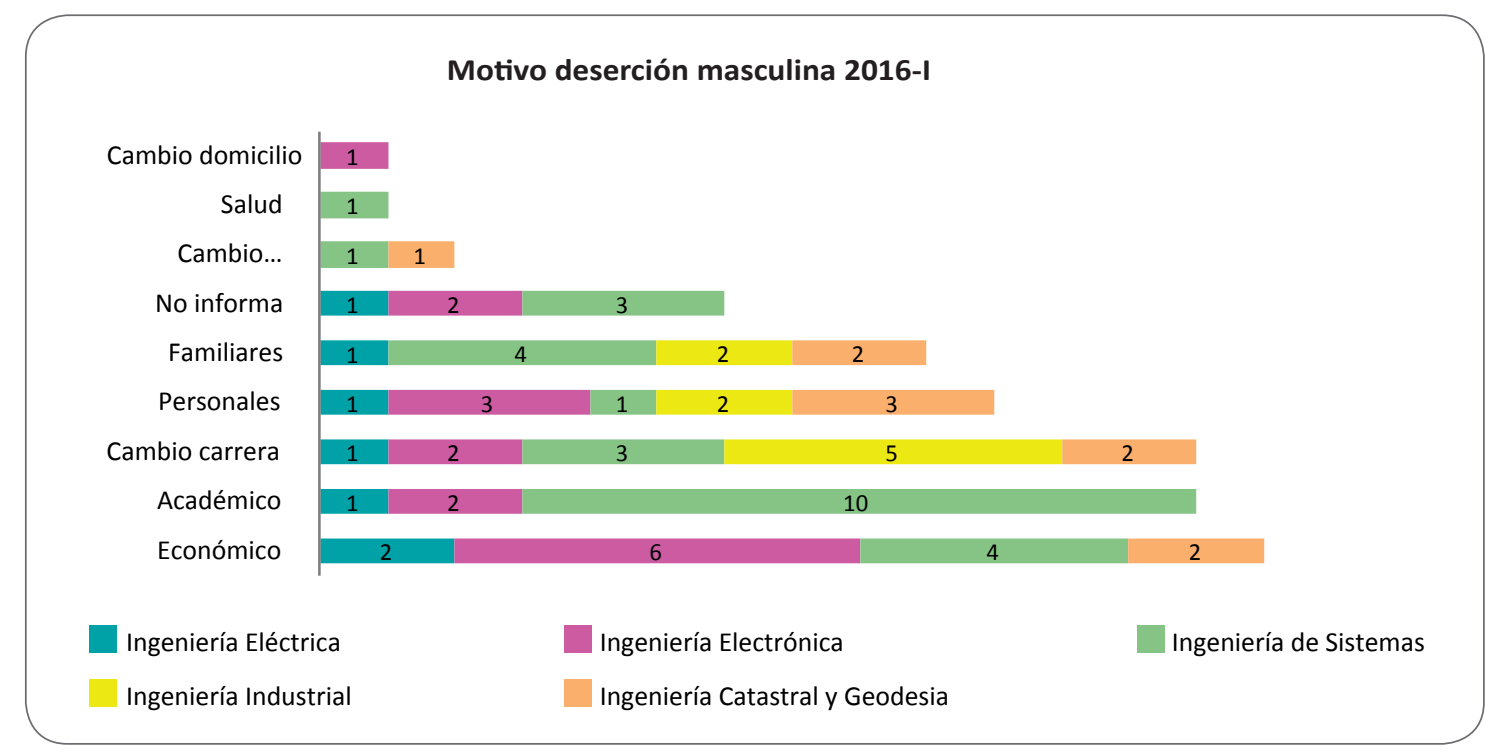

Figura 7. Número de estudiantes desertores en el periodo 2016-I, género masculino, por motivo de retiro correspondiente a cada proyecto curricular en la Facultad de Ingeniería, según actas Consejo de Facultad.

Fuente: elaboración propia

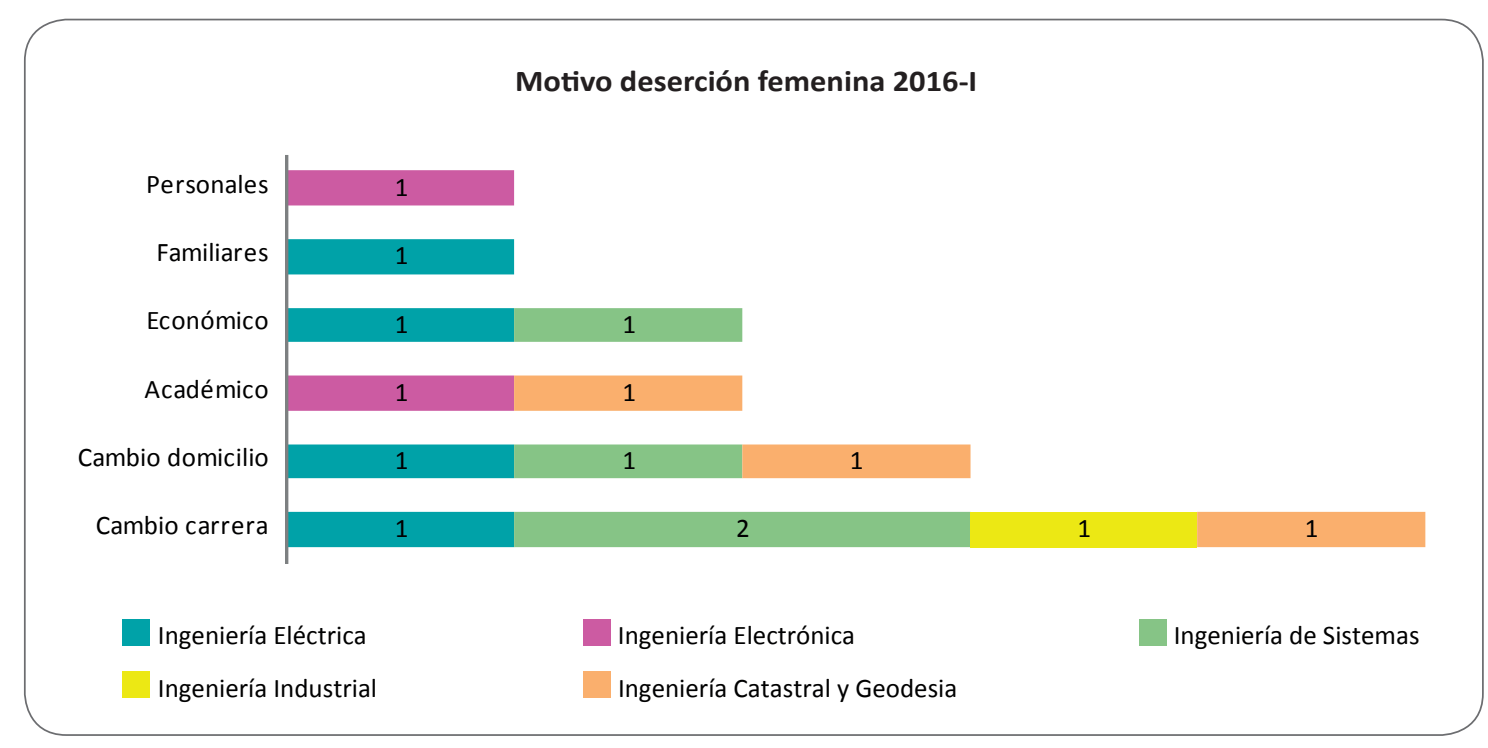

Figura 8. Número de estudiantes desertores en el periodo 2016-I, género femenino, por motivo de retiro correspondiente a cada proyecto curricular en la Facultad de Ingeniería, según actas Consejo de Facultad.

Fuente: elaboración propia

ámbitos Académico y Económico (presentan igual cantidad de desertoras), obteniendo que la tasa de deserción de mujeres en este semestre académico corresponde al $17 \%$. El proyecto curricular de Ingeniería de Sistemas y el de Ingeniería Eléctrica son los de mayor índice de deserción femenina.
Deserción por número de matrículas oficializadas en el 2016-I

En la figura 9, se evidencia la variable del número de estudiantes de género masculino desertores según el número de matrículas oficializadas al 
momento de solicitar el retiro voluntario y definitivo en el periodo académico 2016-I, obteniendo como resultado que el mayor número de solicitudes corresponde a estudiantes que cursaban su tercer semestre académico.
En la figura 10, se ubica el número de matrículas oficializadas por cada estudiante de género femenino desertor en el periodo académico 2016-I, obteniendo como resultado que el mayor número de solicitudes de retiro tratadas en el Consejo de

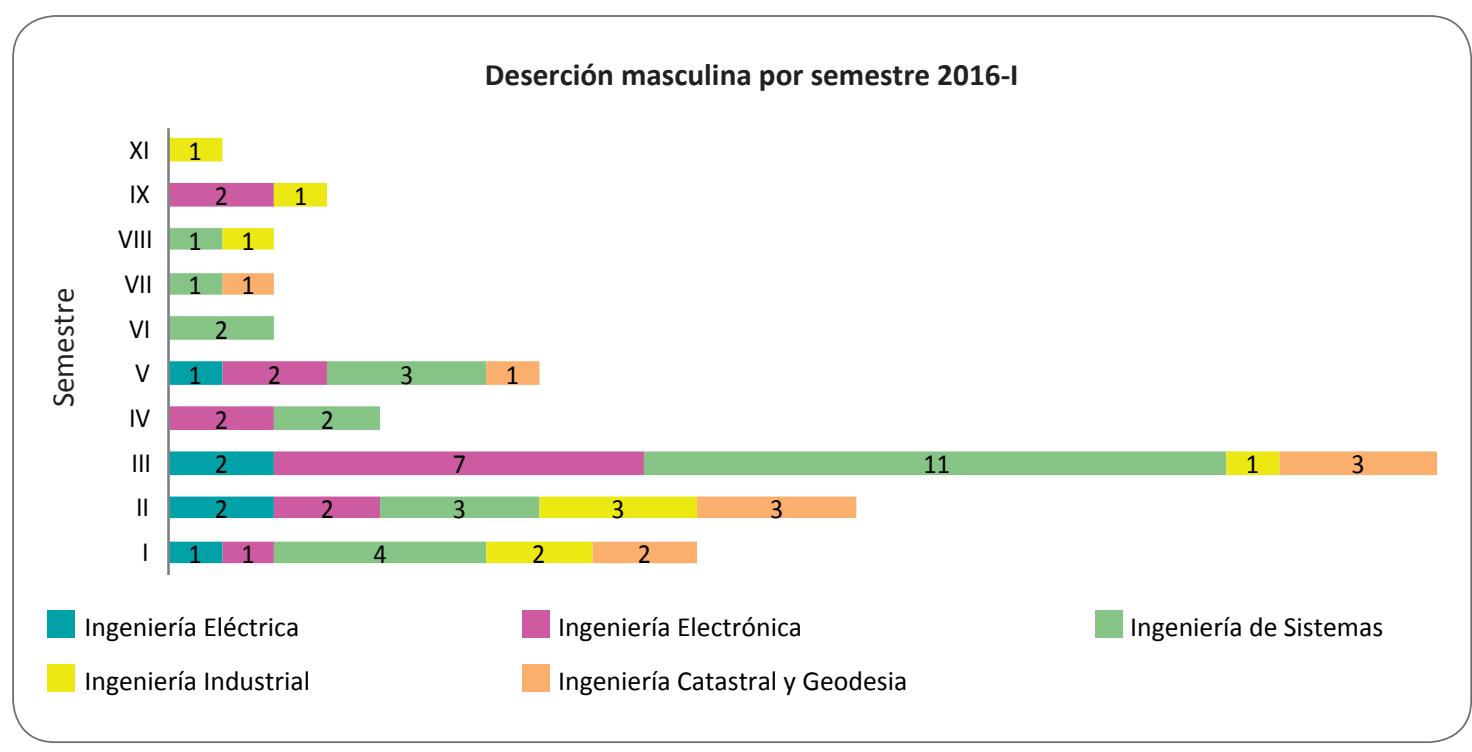

Figura 9. Número de estudiantes hombres desertores en el periodo 2016-I, según el número de matrículas oficializadas de cada proyecto curricular en la Facultad de Ingeniería, según actas Consejo de Facultad.

Fuente: elaboración propia

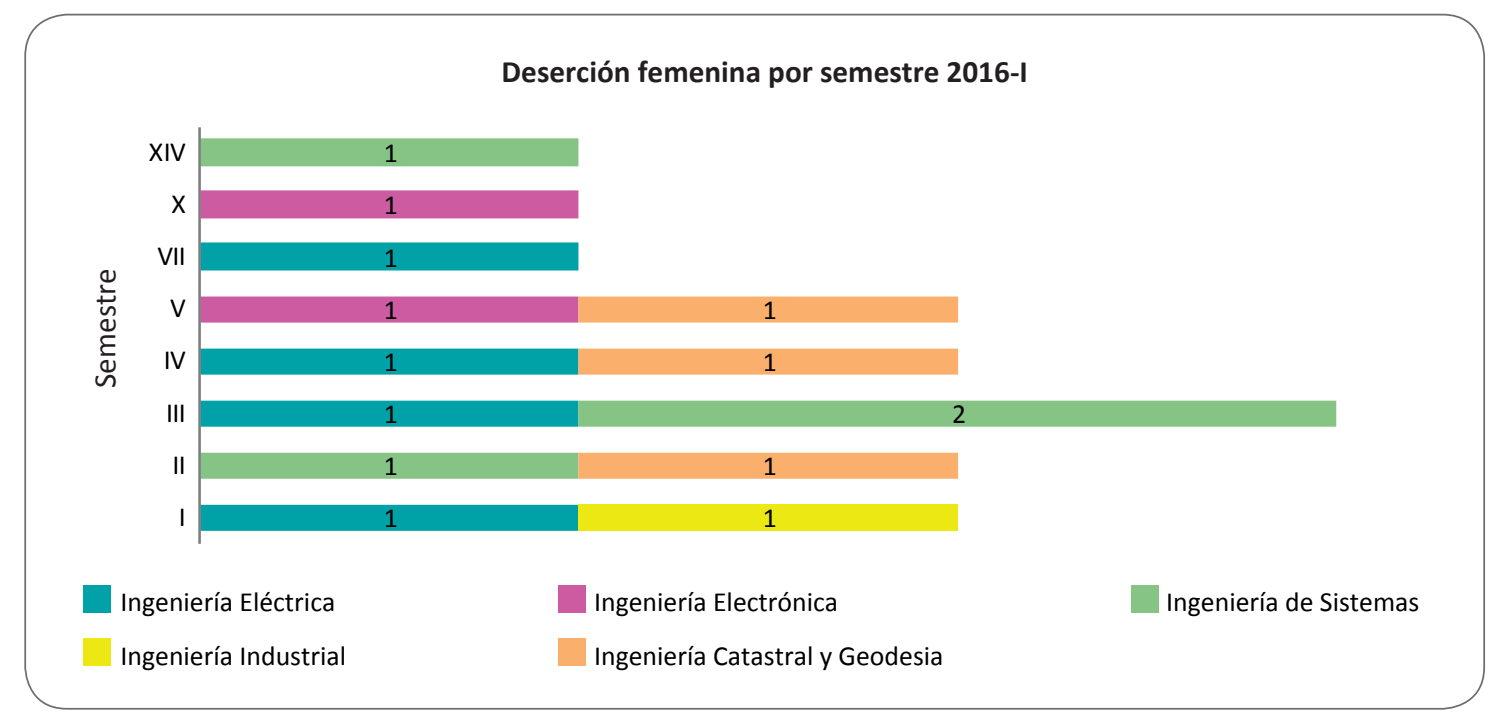

Figura 10. Número de estudiantes mujeres desertoras en el periodo 2016-I, según el número de matrículas oficializadas de cada proyecto curricular en la Facultad de Ingeniería, según actas Consejo de Facultad.

Fuente: elaboración propia 
Facultad corresponde a estudiantes mujeres que cursaban su tercer semestre académico.

\section{Causales de deserción 2016-II}

En la figura 11, se muestra el motivo presentado por estudiantes de género masculino para desertar en el periodo 2016-II. El motivo principal para radicar la solicitud a la Secretaría Académica fue Económico, con un total de 32 de estudiantes (en una población total de 126 estudiantes), seguido por Cambio de carrera (treinta estudiantes) y Ámbito académico (veinte estudiantes). El proyecto curricular que más niveles de desertores tuvo es Ingeniería Electrónica. Para el periodo 2016-II, la tasa de deserción masculina corresponde al $81 \%$ de la población total desertora en este semestre.

En la figura 12, se establecen las causales de deserción radicadas por estudiantes de género femenino en el periodo académico 2016-II, encontrando como principal motivo el Cambio de carrera, con un total de ocho de estudiantes, seguido por Económico, con siete estudiantes, en una población total de veintinueve estudiantes. Los proyectos curriculares de Ingeniería Industrial e Ingeniería Catastral y Geodesia reportan el mismo número de desertoras en este semestre académico, obteniendo que la tasa de deserción de esta población femenina corresponde al $19 \%$.

\section{Deserción por número de matrículas oficializadas en el 2016-II}

En la figura 13, se muestra el número de matrículas oficializadas por estudiantes hombres al momento de requerir el retiro voluntario y definitivo en el semestre académico 2016-II, obteniendo como resultado que el mayor número de solicitudes corresponde a estudiantes que cursaban su segundo semestre académico.

En la figura 14, se analiza el número de matrículas oficializadas por estudiantes de género femenino al momento de desertar en el periodo académico 2016-II, obteniendo como resultado que el mayor número de solicitudes aprobadas en Consejo de Facultad corresponde a estudiantes que cursaban su segundo semestre académico.

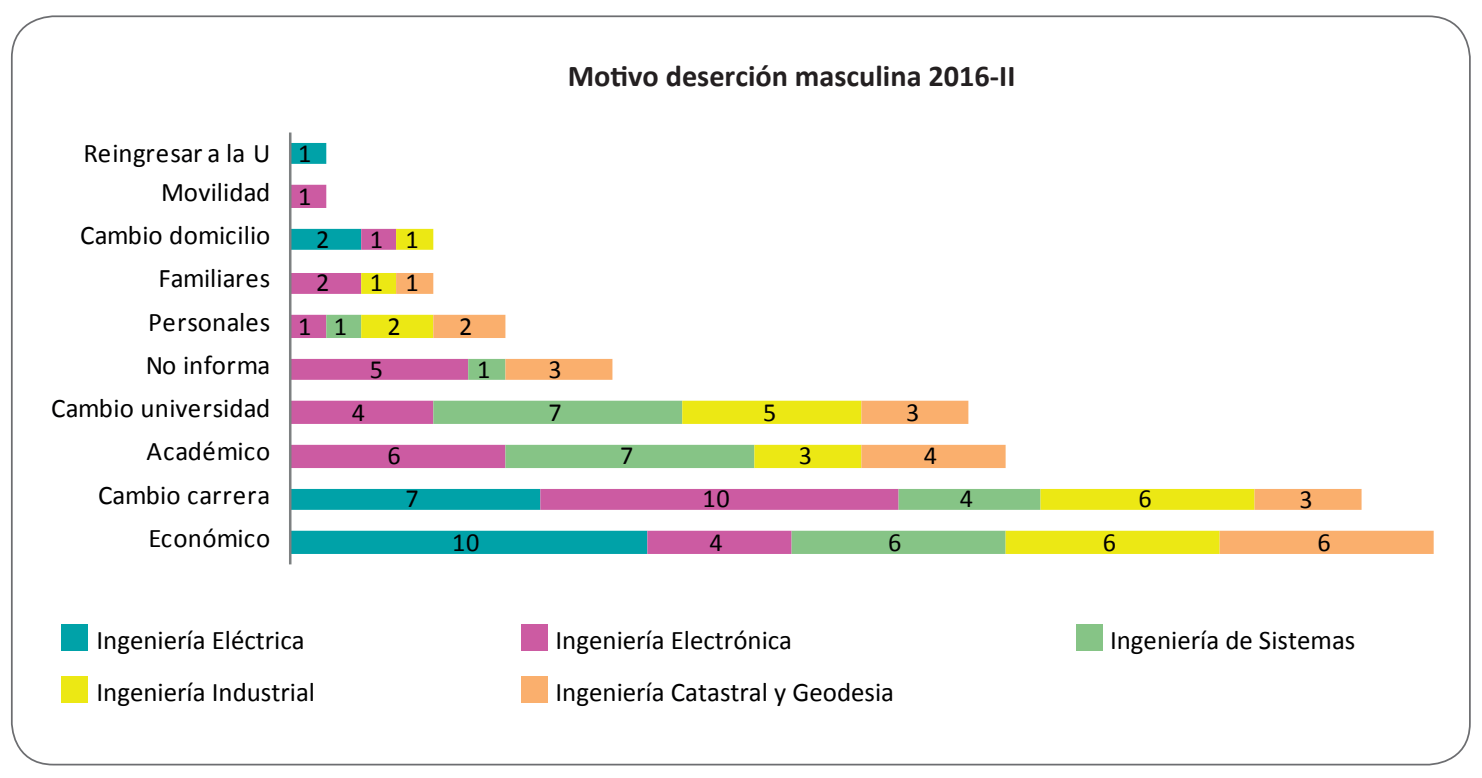

Figura 11. Número de estudiantes desertores en el periodo 2016-II, género masculino, por motivo de retiro correspondiente a cada proyecto curricular en la Facultad de Ingeniería, según actas Consejo de Facultad.

Fuente: elaboración propia 


\section{Motivo deserción femenina 2016-II}

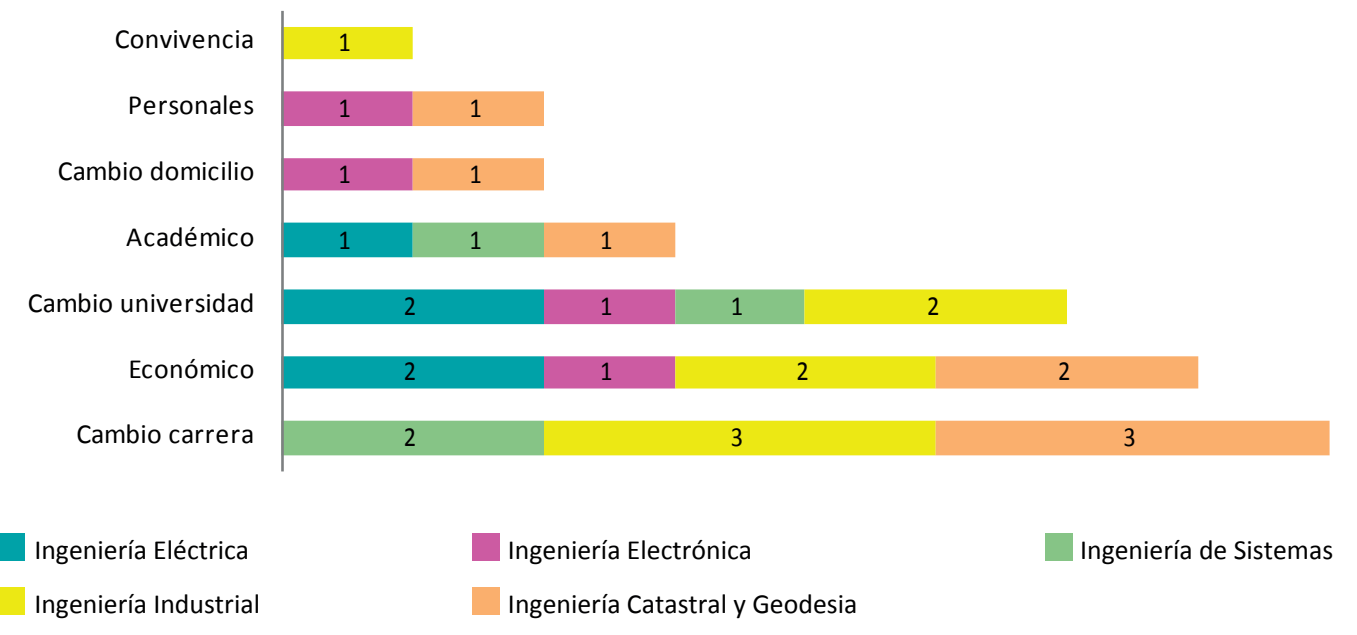

Figura 12. Número de estudiantes desertores en el periodo 2016-II, género femenino, por motivo de retiro correspondiente a cada proyecto curricular en la Facultad de Ingeniería, según actas Consejo de Facultad.

Fuente: elaboración propia

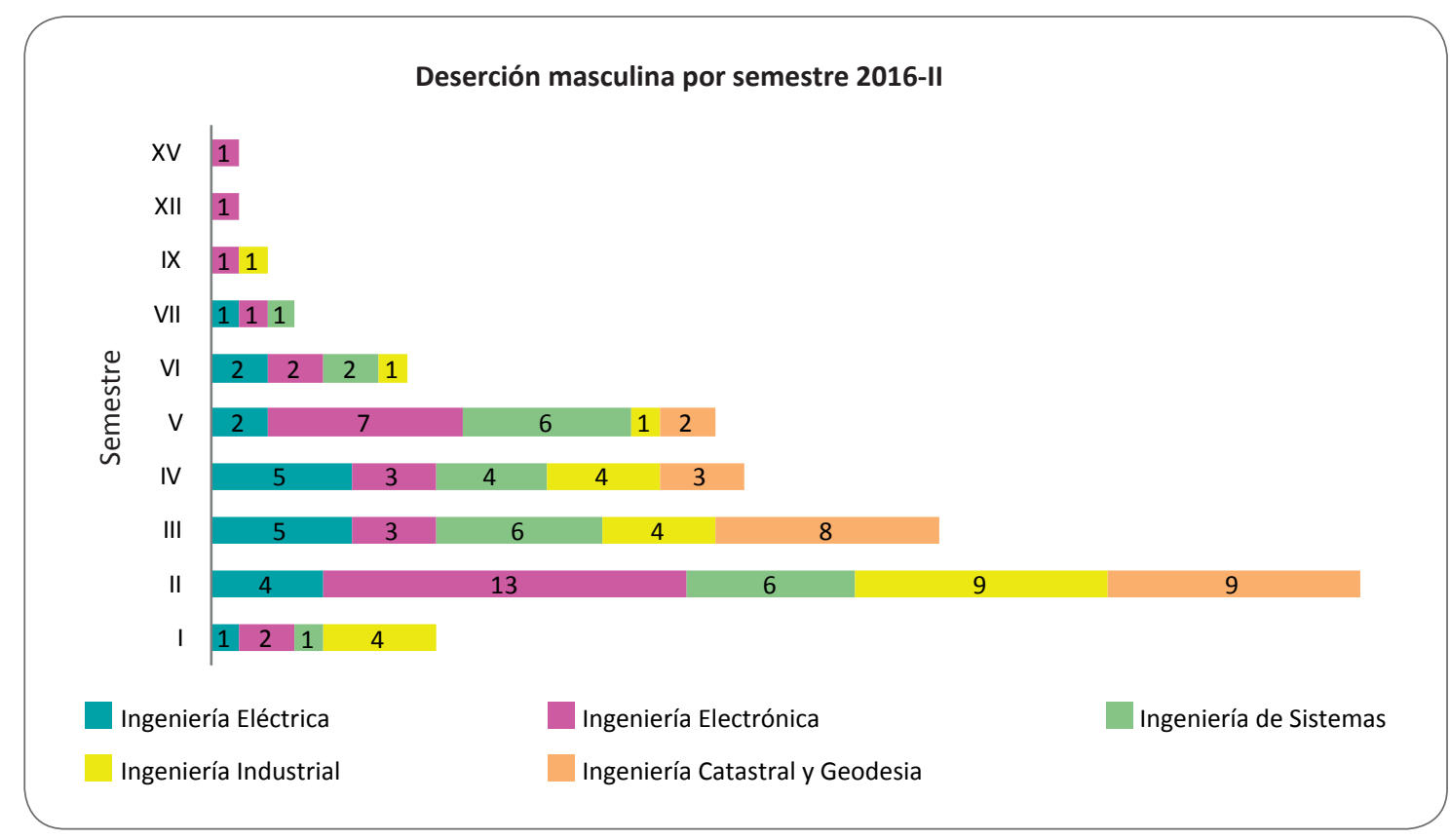

Figura 13. Número de estudiantes hombres desertores en el periodo 2016-II, según el número de matrículas oficializadas de cada proyecto curricular en la Facultad de Ingeniería, según actas Consejo de Facultad.

Fuente: elaboración propia 


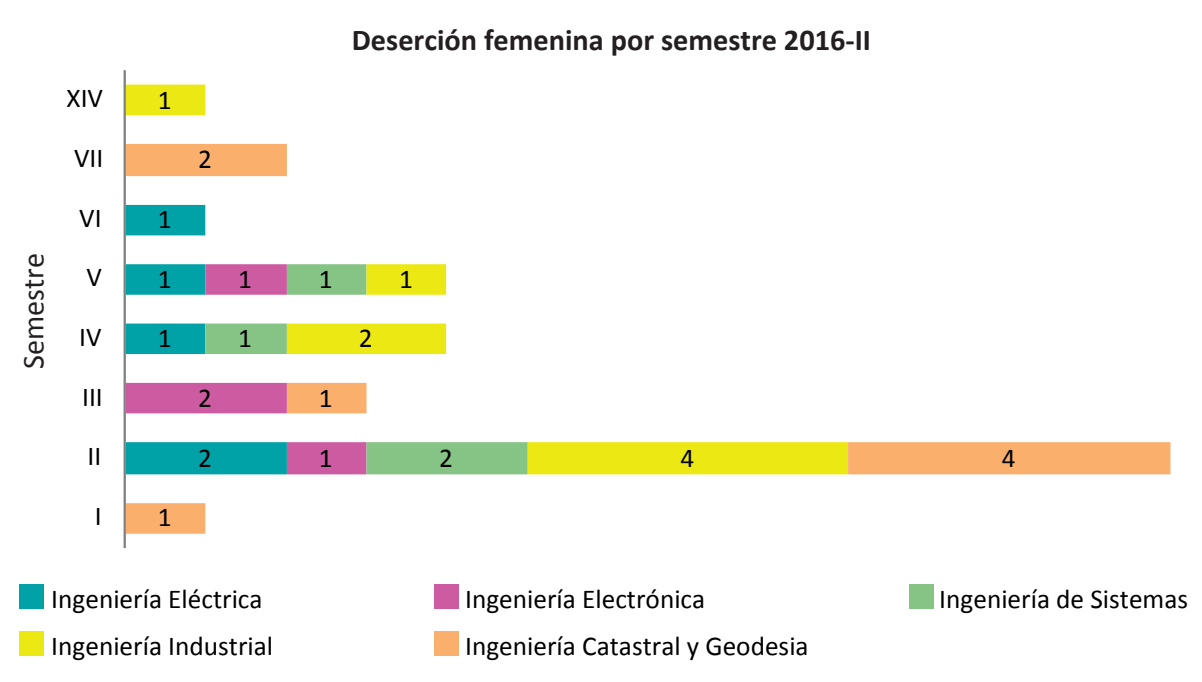

Figura 14. Número de estudiantes mujeres que desertaron en el periodo 2016-II, según el número de matrículas oficializadas de cada proyecto curricular en la Facultad de Ingeniería, según actas Consejo de Facultad.

Fuente: elaboración propia

\section{Causales de deserción 2017-I}

En la figura 15, se muestra el motivo de retiro manifestado por estudiantes hombres en el periodo 2017-I, evidenciando que la principal causa de deserción es Económica, con un total de sesenta estudiantes (en una población total de 168 estudiantes), cuyo valor máximo lo tiene el proyecto curricular Ingeniería de Sistemas. Los factores incidentes que le siguieron son: Cambio de carrera y Académico, con un total de 37 y veintitrés estudiantes, respectivamente. La tasa de deserción corresponde al $88 \%$ de la población total desertora en este semestre.

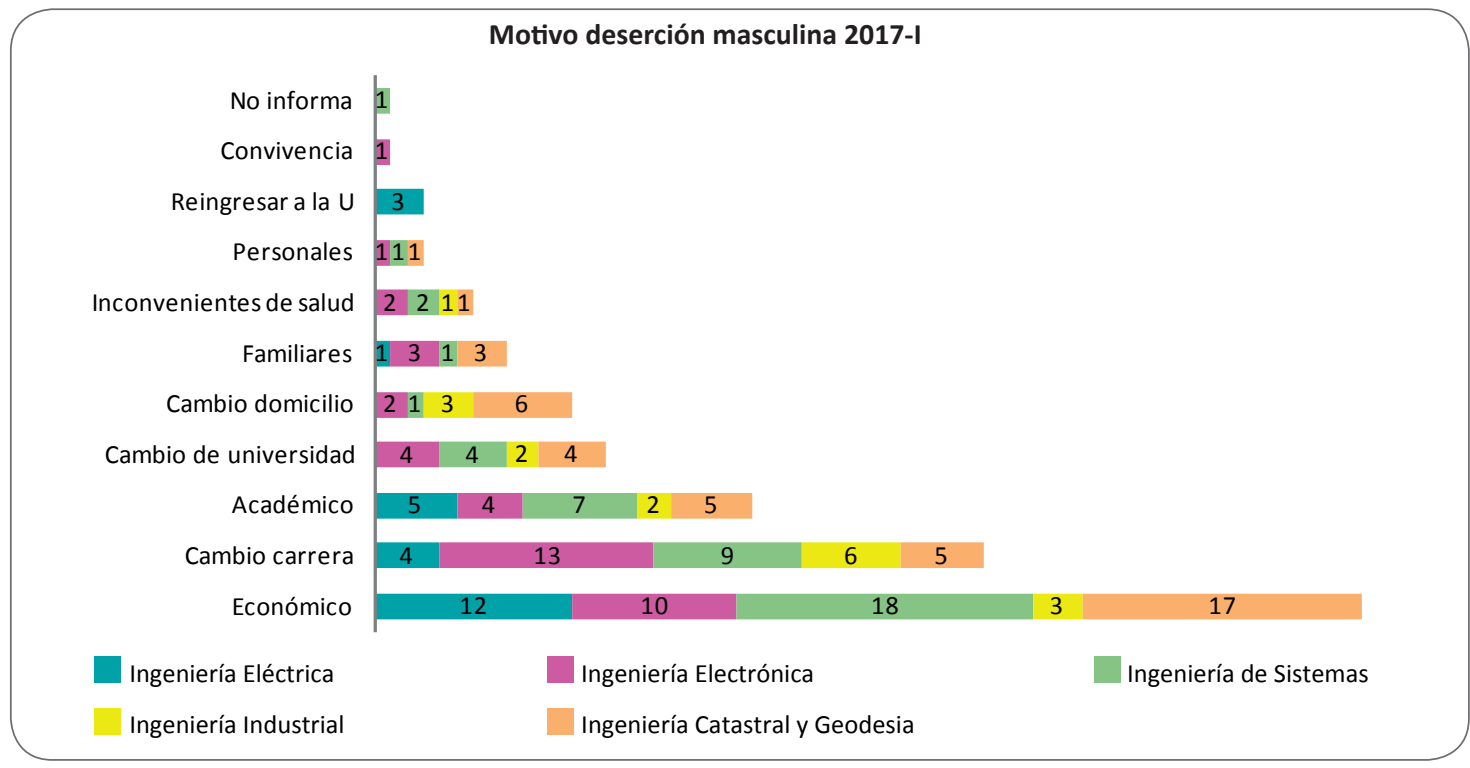

Figura 15. Número de estudiantes desertores en el periodo 2017-I, género masculino, por motivo de retiro correspondiente a cada proyecto curricular en la Facultad de Ingeniería, según actas Consejo de Facultad.

Fuente: elaboración propia 


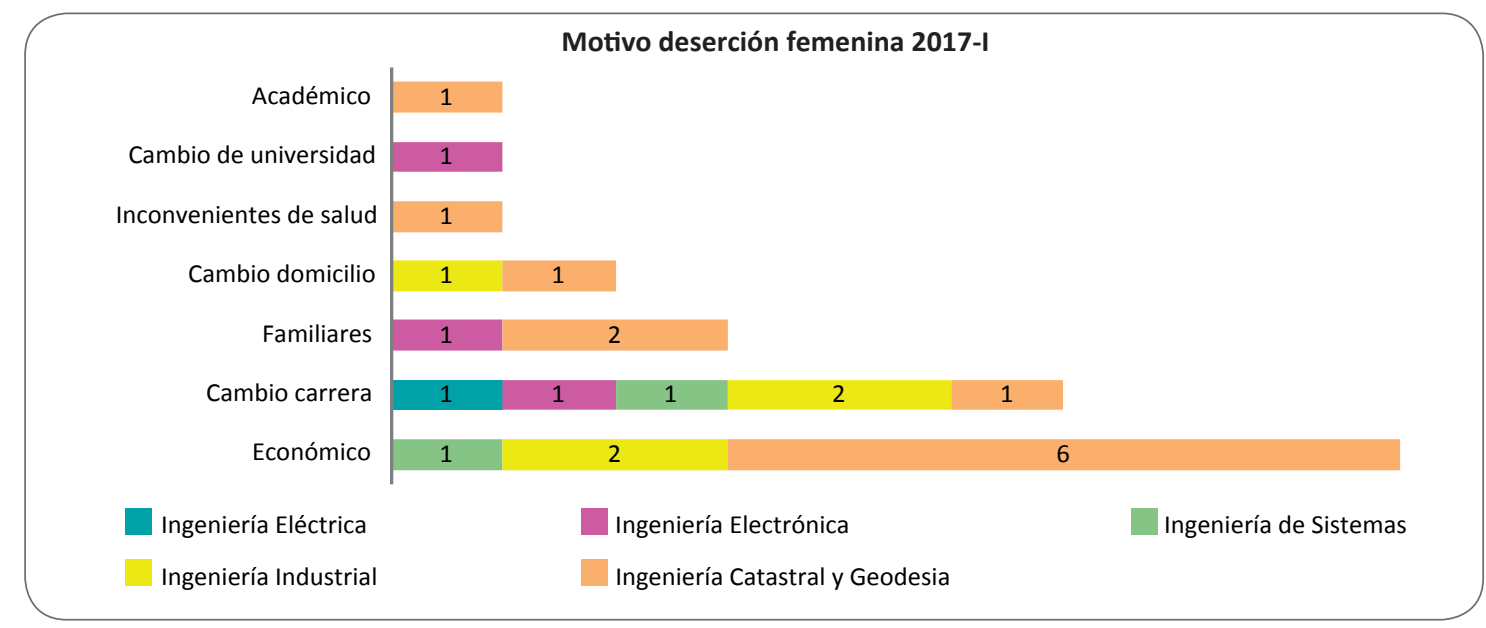

Figura 16. Número de estudiantes desertores en el periodo 2017-I, género femenino, por motivo de retiro correspondiente a cada proyecto curricular en la Facultad de Ingeniería, según actas Consejo de Facultad.

Fuente: elaboración propia

En la figura 16, se muestra la deserción en función de la justificación radicada ante el Consejo de Facultad para retiro voluntario de estudiantes de género femenino; en el periodo 2017-I el motivo de mayor impacto es Económico, seguido de Cambio de carrera, con nueve y seis estudiantes, respectivamente (en una población total de veintitrés estudiantes). El proyecto curricular Ingeniería Catastral y Geodesia presenta la mayor cantidad de solicitudes, y la tasa de deserción de mujeres en ese semestre académico corresponde al 12\% con referencia a la población total desertora en ese periodo.

Deserción por número de matrículas

oficializadas en el 2017-I

En la figura 17, se muestra el número de matrículas oficializadas por los estudiantes hombres al momento de solicitar su retiro voluntario en el semestre académico 2017-I, obteniendo el mayor número de solicitudes de estudiantes que cursaban su segundo periodo académico.

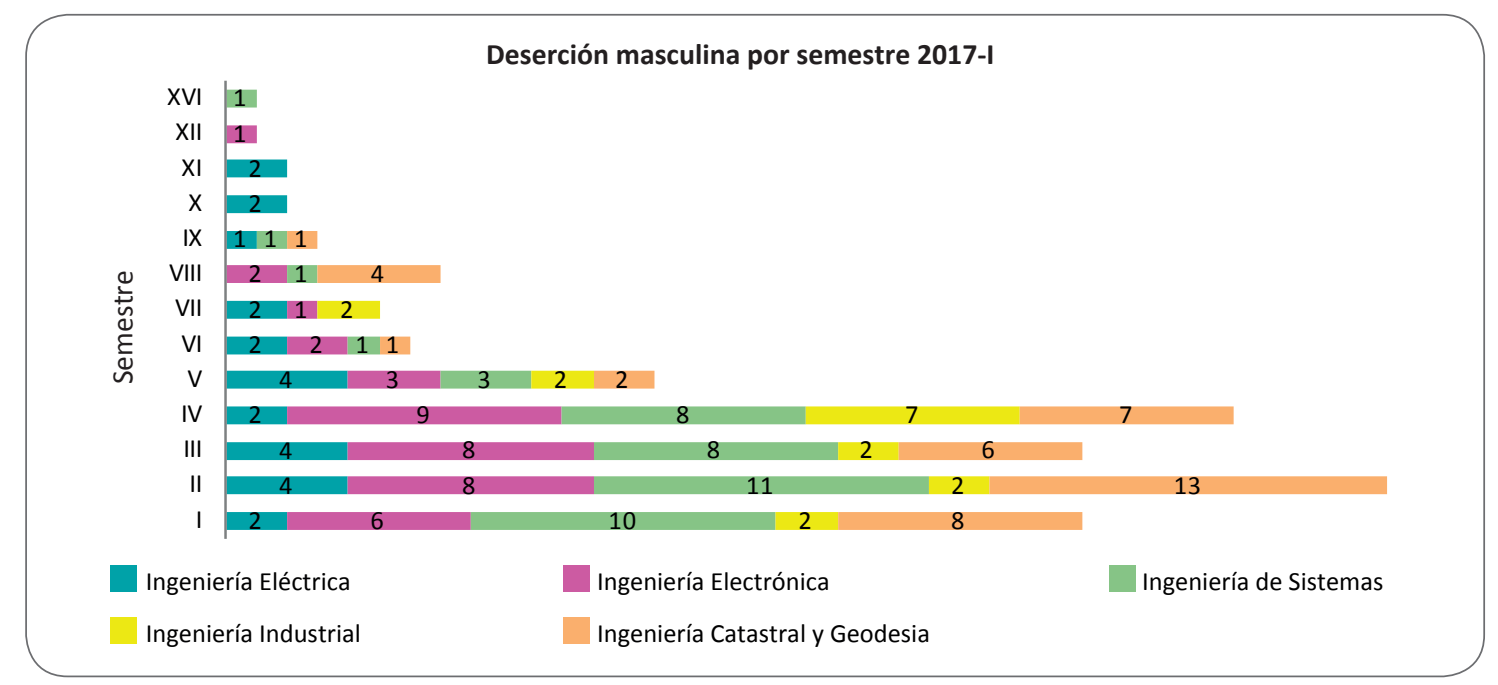

Figura 17. Número de estudiantes hombres desertores en el periodo 2017-I, según el número de matrículas oficializadas de cada proyecto curricular en la Facultad de Ingeniería, según actas Consejo de Facultad.

Fuente: elaboración propia 


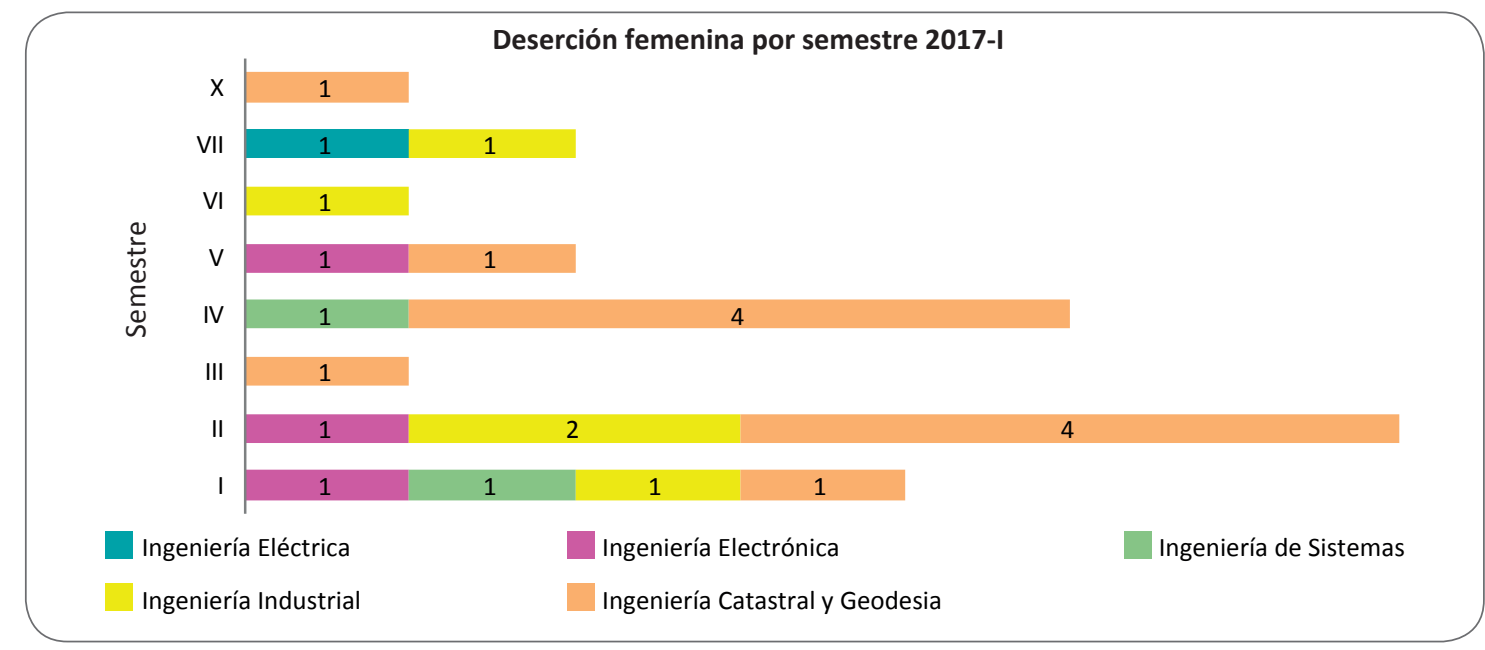

Figura 18. Número de estudiantes mujeres que desertaron en el periodo 2017-I, según el número de matrículas oficializadas de cada proyecto curricular en la Facultad de Ingeniería, según actas Consejo de Facultad.

Fuente: elaboración propia

En la figura 18, se ubica el número de matrículas oficializadas por cada estudiante de género femenino en el periodo académico 2017-I al momento de desertar, analizando que el mayor número de solicitudes fueron de estudiantes que cursaban el segundo semestre.

\subsection{Estadísticas de deserción en pregrados de Ingeniería en Colombia}

Con apoyo en la herramienta SPADIEs 3.0, se obtuvieron las tasas de deserción en universidades de carácter oficial donde se imparten programas curriculares de Ingeniería, diferenciadas por año y género, lo que permitió condensar la información en la tabla 5 .

Según las tasas de deserción de la tabla 5, se puede concluir que las universidades reportan, en la mayoría de los casos, un máximo de $10 \%$ de deserción anual por género. Algunas de las que se mantienen en $10-20 \%$ de esta tasa son: Universidad de Antioquia, Universidad de Cartagena, Universidad de La Guajira, Universidad de Pamplona, Universidad del Pacífico, Universidad del Quindío, Universidad Francisco de Paula Santander, Universidad Popular del Cesar, Universidad Tecnológica de Pereira y Universidad Tecnológica del Chocó.

Tabla 5. Deserción en universidades de carácter oficial de Colombia en programas de pregrado de Ingeniería, discriminado por género (F: Femenino, M: Masculino).

\begin{tabular}{|c|c|c|c|c|c|c|c|c|c|c|c|}
\hline Nombre institución & G & 2012-I & 2012-II & 2013-I & 2013-II & 2014-I & 2014-II & 2015-I & 2015-II & 2016-I & 2016-II \\
\hline \multirow{2}{*}{ Universidad de Antioquia } & $\mathrm{F}$ & $13 \%$ & $10 \%$ & $11 \%$ & $10 \%$ & $11 \%$ & $10 \%$ & $13 \%$ & $12 \%$ & $13 \%$ & $8 \%$ \\
\hline & M & $15,89 \%$ & $9,84 \%$ & $15,31 \%$ & $13,77 \%$ & $14,24 \%$ & $10,55 \%$ & $14,53 \%$ & $11,88 \%$ & $11,78 \%$ & $7,84 \%$ \\
\hline \multirow{2}{*}{ Universidad de Caldas } & $\mathrm{F}$ & $4,83 \%$ & $4,70 \%$ & $3 \%$ & $5,04 \%$ & $3,66 \%$ & $8,30 \%$ & $10,36 \%$ & $6,05 \%$ & $8,24 \%$ & $9,38 \%$ \\
\hline & $\mathrm{M}$ & $6,58 \%$ & $8,71 \%$ & $6,85 \%$ & $9,03 \%$ & $6,2 \%$ & $8,96 \%$ & $9,34 \%$ & $6,74 \%$ & $6,96 \%$ & $5,44 \%$ \\
\hline \multirow{2}{*}{ Universidad de Cartagena } & $\mathrm{F}$ & $11,04 \%$ & $13,35 \%$ & $12,92 \%$ & $10,80 \%$ & $9,34 \%$ & $6,77 \%$ & $10,36 \%$ & $11,08 \%$ & $11,36 \%$ & $13 \%$ \\
\hline & $\mathrm{M}$ & $11,94 \%$ & $15,48 \%$ & $16,17 \%$ & $14,08 \%$ & $13,02 \%$ & $10,28 \%$ & $12,89 \%$ & $12,03 \%$ & $10,19 \%$ & $11,56 \%$ \\
\hline \multirow{2}{*}{ Universidad de Córdoba } & $\mathrm{F}$ & $10,89 \%$ & $11,58 \%$ & $7,79 \%$ & $5,93 \%$ & $6,56 \%$ & $11,59 \%$ & $8,22 \%$ & $8,84 \%$ & $9,25 \%$ & $0 \%$ \\
\hline & $\mathrm{M}$ & $13,77 \%$ & $14,56 \%$ & $10,5 \%$ & $7,53 \%$ & $8,74 \%$ & $14,08 \%$ & $7 \%$ & $7,56 \%$ & $6,39 \%$ & $0 \%$ \\
\hline \multirow{2}{*}{$\begin{array}{l}\text { Universidad de Cundinamarca- } \\
\text { UDEC }\end{array}$} & $\mathrm{F}$ & $9 \%$ & $7 \%$ & $6 \%$ & $8 \%$ & $8 \%$ & $9 \%$ & $11 \%$ & $11 \%$ & $9 \%$ & $10 \%$ \\
\hline & $\mathrm{M}$ & $13,01 \%$ & $11,53 \%$ & $7,33 \%$ & $11,61 \%$ & $11,43 \%$ & $10,78 \%$ & $9,71 \%$ & $9,52 \%$ & $8,73 \%$ & $7,8 \%$ \\
\hline
\end{tabular}


(viene)

\begin{tabular}{|c|c|c|c|c|c|c|c|c|c|c|c|}
\hline Nombre institución & G & 2012-I & 2012-II & 2013-I & 2013-II & 2014-I & 2014-II & 2015-I & 2015-II & 2016-I & 2016-II \\
\hline \multirow{2}{*}{ Universidad de la Amazonia } & $\mathrm{F}$ & $4,34 \%$ & $8,66 \%$ & $3,93 \%$ & $9,07 \%$ & $5,85 \%$ & $6,90 \%$ & $7,92 \%$ & $7,50 \%$ & $10,02 \%$ & $13,89 \%$ \\
\hline & M & $11,11 \%$ & $7,95 \%$ & $12,18 \%$ & $9,59 \%$ & $8,55 \%$ & $10,11 \%$ & $6,87 \%$ & $6,67 \%$ & $7,19 \%$ & $11,86 \%$ \\
\hline \multirow{2}{*}{ Universidad de La Guajira } & $\mathrm{F}$ & $15,89 \%$ & $16,65 \%$ & $12,87 \%$ & $11,65 \%$ & $11,05 \%$ & $11,18 \%$ & $15,55 \%$ & $12,07 \%$ & $12,93 \%$ & $13,05 \%$ \\
\hline & M & $21,23 \%$ & $20,12 \%$ & $17,73 \%$ & $17,04 \%$ & $16,13 \%$ & $14,9 \%$ & $16,34 \%$ & $12,22 \%$ & $11,75 \%$ & $11,35 \%$ \\
\hline \multirow{2}{*}{ Universidad de los Llanos } & $\mathrm{F}$ & $7,83 \%$ & $6,75 \%$ & $7 \%$ & $5,44 \%$ & $4,80 \%$ & $7,76 \%$ & $10 \%$ & $8,10 \%$ & $12,68 \%$ & $11,30 \%$ \\
\hline & M & $12,7 \%$ & $10,58 \%$ & $10,22 \%$ & $9,67 \%$ & $9,01 \%$ & $8,83 \%$ & $8,29 \%$ & $6,93 \%$ & $5,95 \%$ & $5,77 \%$ \\
\hline \multirow{2}{*}{ Universidad de Nariño } & $\mathrm{F}$ & $0 \%$ & $10 \%$ & $0 \%$ & $8,51 \%$ & $2,27 \%$ & $6,35 \%$ & $0 \%$ & $6,74 \%$ & $2,47 \%$ & $8,70 \%$ \\
\hline & M & $0 \%$ & $36,36 \%$ & $0 \%$ & $15,15 \%$ & $3,45 \%$ & $9,38 \%$ & $3,57 \%$ & $2,53 \%$ & $2,63 \%$ & $5,21 \%$ \\
\hline \multirow{2}{*}{ Universidad de Pamplona } & $\mathrm{F}$ & $10,21 \%$ & $10,91 \%$ & $9,44 \%$ & $9,10 \%$ & $11,56 \%$ & $10,38 \%$ & $12,83 \%$ & $11,55 \%$ & $17,76 \%$ & $11,63 \%$ \\
\hline & M & $13,05 \%$ & $14,68 \%$ & $8,86 \%$ & $8,97 \%$ & $12,17 \%$ & $9,37 \%$ & $9,93 \%$ & $10,33 \%$ & $12,86 \%$ & $9,91 \%$ \\
\hline \multirow{2}{*}{ Universidad de Sucre } & $\mathrm{F}$ & $6,37 \%$ & $7,71 \%$ & $25,74 \%$ & $4,75 \%$ & $7,74 \%$ & $3,36 \%$ & $6,98 \%$ & $3,99 \%$ & $6,51 \%$ & $11,55 \%$ \\
\hline & M & $7,26 \%$ & $7,1 \%$ & $16,55 \%$ & $5,77 \%$ & $5,71 \%$ & $6,77 \%$ & $4,76 \%$ & $4,81 \%$ & $5,08 \%$ & $13 \%$ \\
\hline \multirow{2}{*}{ Universidad del Atlántico } & F & $6,86 \%$ & $7,55 \%$ & $5,25 \%$ & $7,64 \%$ & $8,33 \%$ & $6,57 \%$ & $7,91 \%$ & $7,57 \%$ & $8,81 \%$ & $8,93 \%$ \\
\hline & M & $8,74 \%$ & $10,28 \%$ & $7,51 \%$ & $10,39 \%$ & $9,44 \%$ & $9,64 \%$ & $10,01 \%$ & $8,47 \%$ & $10,21 \%$ & $10,95 \%$ \\
\hline \multirow{2}{*}{ Universidad del Cauca } & $\mathrm{F}$ & $3,39 \%$ & $5,65 \%$ & $3,85 \%$ & $6,01 \%$ & $5,97 \%$ & $5,24 \%$ & $6,21 \%$ & $6,39 \%$ & $5,14 \%$ & $5 \%$ \\
\hline & $\mathrm{M}$ & $5,3 \%$ & $6,87 \%$ & $6,11 \%$ & $6,59 \%$ & $7,58 \%$ & $6,31 \%$ & $5,24 \%$ & $5,07 \%$ & $4,76 \%$ & $5,46 \%$ \\
\hline \multirow{2}{*}{ Universidad del Magdalena } & F & $10,65 \%$ & $7,04 \%$ & $6,36 \%$ & $7,75 \%$ & $7,02 \%$ & $8,19 \%$ & $6,87 \%$ & $8,76 \%$ & $9,83 \%$ & $0 \%$ \\
\hline & M & $12,83 \%$ & $9,87 \%$ & $7,5 \%$ & $8,36 \%$ & $8,41 \%$ & $6,47 \%$ & $6,17 \%$ & $6,46 \%$ & $7,26 \%$ & $0 \%$ \\
\hline \multirow{2}{*}{ Universidad del Pacífico } & F & $14,38 \%$ & $0 \%$ & $27 \%$ & $27,63 \%$ & $18,13 \%$ & $16,18 \%$ & $15,41 \%$ & $12,76 \%$ & $12,68 \%$ & $16 \%$ \\
\hline & $\mathrm{M}$ & $15,21 \%$ & $0 \%$ & $26,65 \%$ & $35,32 \%$ & $20,33 \%$ & $12,94 \%$ & $16 \%$ & $15,51 \%$ & $13,65 \%$ & $14,09 \%$ \\
\hline \multirow{2}{*}{ Universidad del Quindío } & F & $11,37 \%$ & $12 \%$ & $8,67 \%$ & $7,69 \%$ & $9,47 \%$ & $13,52 \%$ & $11,11 \%$ & $13,51 \%$ & $11,74 \%$ & $13,70 \%$ \\
\hline & M & $15,74 \%$ & $16,76 \%$ & $13,87 \%$ & $14,53 \%$ & $14,35 \%$ & $14,42 \%$ & $11,17 \%$ & $12,74 \%$ & $9,87 \%$ & $11,54 \%$ \\
\hline \multirow{2}{*}{ Universidad del Tolima } & F & $11,05 \%$ & $5,36 \%$ & $14,86 \%$ & $6,86 \%$ & $5,85 \%$ & $8,63 \%$ & $6,35 \%$ & $5,74 \%$ & $6,63 \%$ & $11,13 \%$ \\
\hline & $\mathrm{M}$ & $15,71 \%$ & $7,55 \%$ & $17,78 \%$ & $7,89 \%$ & $6,16 \%$ & $6,48 \%$ & $5,71 \%$ & $7,34 \%$ & $5,47 \%$ & $9,99 \%$ \\
\hline \multirow{2}{*}{ Universidad del Valle } & F & $6 \%$ & $4 \%$ & $5,70 \%$ & $6,25 \%$ & $5 \%$ & $5 \%$ & $5 \%$ & $6 \%$ & $7 \%$ & $0 \%$ \\
\hline & M & $8,5 \%$ & $6,28 \%$ & $8,01 \%$ & $8,14 \%$ & $7,11 \%$ & $8,05 \%$ & $7,99 \%$ & $6,59 \%$ & $7,57 \%$ & $0 \%$ \\
\hline \multirow{2}{*}{$\begin{array}{l}\text { Universidad Distrital Francisco } \\
\text { José de Caldas }\end{array}$} & $\mathrm{F}$ & $5 \%$ & $4 \%$ & $6,67 \%$ & $10,73 \%$ & $11 \%$ & $7 \%$ & $9 \%$ & $8 \%$ & $8 \%$ & $10 \%$ \\
\hline & M & $6,5 \%$ & $5,07 \%$ & $8,56 \%$ & $14,68 \%$ & $16,83 \%$ & $11,19 \%$ & $9,75 \%$ & $9,21 \%$ & $7,92 \%$ & $9,18 \%$ \\
\hline \multirow{2}{*}{$\begin{array}{l}\text { Universidad Francisco de Paula } \\
\text { Santander }\end{array}$} & $\mathrm{F}$ & $10 \%$ & $10 \%$ & $12,26 \%$ & $11,02 \%$ & $9 \%$ & $10 \%$ & $9 \%$ & $8 \%$ & $7 \%$ & $8 \%$ \\
\hline & M & $11,79 \%$ & $13,02 \%$ & $15,71 \%$ & $15,14 \%$ & $8,42 \%$ & $11,04 \%$ & $8,34 \%$ & $7,61 \%$ & $6,2 \%$ & $6,22 \%$ \\
\hline \multirow{2}{*}{$\begin{array}{l}\text { Universidad Industrial de } \\
\text { Santander }\end{array}$} & F & $5,41 \%$ & $6,68 \%$ & $5,23 \%$ & $6,15 \%$ & $5,59 \%$ & $5,35 \%$ & $3,86 \%$ & $9,05 \%$ & $6,59 \%$ & $8,48 \%$ \\
\hline & $\mathrm{M}$ & $6,89 \%$ & $8,56 \%$ & $7,93 \%$ & $8,49 \%$ & $7,29 \%$ & $5,83 \%$ & $4,95 \%$ & $8,24 \%$ & $5,01 \%$ & $7,55 \%$ \\
\hline \multirow{2}{*}{$\begin{array}{l}\text { Universidad Militar Nueva } \\
\text { Granada }\end{array}$} & $\mathrm{F}$ & $6,61 \%$ & $6,71 \%$ & $6,75 \%$ & $6,91 \%$ & $5,11 \%$ & $9,53 \%$ & $7,82 \%$ & $10,64 \%$ & $41,77 \%$ & $27,48 \%$ \\
\hline & $\mathrm{M}$ & $10,63 \%$ & $7,73 \%$ & $8,98 \%$ & $8,68 \%$ & $8,59 \%$ & $10,75 \%$ & $9,77 \%$ & $11,08 \%$ & $38,04 \%$ & $23,06 \%$ \\
\hline \multirow{2}{*}{$\begin{array}{l}\text { Universidad Nacional de } \\
\text { Colombia-Bogotá }\end{array}$} & F & $0 \%$ & $0 \%$ & $0 \%$ & $0 \%$ & $0 \%$ & $0 \%$ & $7,14 \%$ & $8,33 \%$ & $9,32 \%$ & $14,29 \%$ \\
\hline & M & $0 \%$ & $0 \%$ & $0 \%$ & $0 \%$ & $0 \%$ & $21,62 \%$ & $15,12 \%$ & $14,81 \%$ & $4,88 \%$ & $9,84 \%$ \\
\hline \multirow{2}{*}{$\begin{array}{l}\text { Universidad Nacional de } \\
\text { Colombia-Antioquia }\end{array}$} & F & $6,03 \%$ & $5,33 \%$ & $6,39 \%$ & $6,52 \%$ & $5,47 \%$ & $6,88 \%$ & $6,73 \%$ & $7,44 \%$ & $6,74 \%$ & $8,42 \%$ \\
\hline & $\mathrm{M}$ & $9,03 \%$ & $7,69 \%$ & $8,99 \%$ & $8,77 \%$ & $8,47 \%$ & $7,92 \%$ & $8,49 \%$ & $7,85 \%$ & $4,78 \%$ & $8,21 \%$ \\
\hline \multirow{2}{*}{$\begin{array}{l}\text { Universidad Nacional de } \\
\text { Colombia-Caldas }\end{array}$} & F & $3,87 \%$ & $5,02 \%$ & $4,91 \%$ & $5,15 \%$ & $4,48 \%$ & $6,20 \%$ & $4,24 \%$ & $5,43 \%$ & $6,41 \%$ & $4,84 \%$ \\
\hline & M & $6,54 \%$ & $6,57 \%$ & $5,62 \%$ & $5,25 \%$ & $6,04 \%$ & $5,32 \%$ & $5,2 \%$ & $5,34 \%$ & $3,74 \%$ & $4,16 \%$ \\
\hline \multirow{2}{*}{$\begin{array}{l}\text { Universidad Nacional de } \\
\text { Colombia-Valle del Cauca }\end{array}$} & F & $4,50 \%$ & $5,42 \%$ & $4,24 \%$ & $4,01 \%$ & $4,09 \%$ & $4,41 \%$ & $4,70 \%$ & $3,92 \%$ & $5,51 \%$ & $3,45 \%$ \\
\hline & $\mathrm{M}$ & $6,44 \%$ & $6,64 \%$ & $7,92 \%$ & $6,56 \%$ & $6,33 \%$ & $6,24 \%$ & $5,13 \%$ & $4,98 \%$ & $4,12 \%$ & $3,89 \%$ \\
\hline & F & $4,30 \%$ & $7,37 \%$ & $4 \%$ & $4 \%$ & $2,97 \%$ & $1,88 \%$ & $4,69 \%$ & $4 \%$ & $5 \%$ & $4,40 \%$ \\
\hline Tecnológica de Colombia-U & M & $7,27 \%$ & $12,46 \%$ & $5,16 \%$ & $5,12 \%$ & $5,18 \%$ & $2,82 \%$ & $5,69 \%$ & $3,12 \%$ & $3,83 \%$ & $3,2 \%$ \\
\hline
\end{tabular}


(viene)

\begin{tabular}{|c|c|c|c|c|c|c|c|c|c|c|c|}
\hline Nombre institución & G & 2012-I & 2012-II & 2013-I & 2013-II & 2014-I & 2014-II & 2015-I & 2015-II & 2016-I & 2016-II \\
\hline \multirow{2}{*}{ Universidad Popular del Cesar } & $\mathrm{F}$ & $8,89 \%$ & $11,91 \%$ & $10,92 \%$ & $9,03 \%$ & $10,18 \%$ & $11,64 \%$ & $15,81 \%$ & $10,18 \%$ & $10,82 \%$ & $14,23 \%$ \\
\hline & M & $12,83 \%$ & $13,18 \%$ & $15,06 \%$ & $14,07 \%$ & $13,69 \%$ & $16,26 \%$ & $13,98 \%$ & $12,33 \%$ & $12,48 \%$ & $10,72 \%$ \\
\hline \multirow{2}{*}{ Universidad Surcolombiana } & $\mathrm{F}$ & $5,81 \%$ & $5,65 \%$ & $6,49 \%$ & $7,07 \%$ & $10,33 \%$ & $8,57 \%$ & $10,53 \%$ & $7,29 \%$ & $11,11 \%$ & $11,12 \%$ \\
\hline & M & $4,68 \%$ & $4,77 \%$ & $6,55 \%$ & $4,97 \%$ & $12,1 \%$ & $8,45 \%$ & $8,43 \%$ & $6,81 \%$ & $8,29 \%$ & $9,21 \%$ \\
\hline \multirow{2}{*}{$\begin{array}{l}\text { Universidad Tecnológica } \\
\text { de Pereira }\end{array}$} & $\mathrm{F}$ & $7,36 \%$ & $10,71 \%$ & $7,98 \%$ & $6,91 \%$ & $8,40 \%$ & $2,22 \%$ & $9,66 \%$ & $6,77 \%$ & $8,84 \%$ & $9,41 \%$ \\
\hline & M & $9,71 \%$ & $11,97 \%$ & $8,68 \%$ & $8,59 \%$ & $10,05 \%$ & $2,3 \%$ & $11,71 \%$ & $6,78 \%$ & $7,59 \%$ & $8,04 \%$ \\
\hline \multirow{2}{*}{$\begin{array}{l}\text { Universidad Tecnológica } \\
\text { del Chocó }\end{array}$} & $\mathrm{F}$ & $14,03 \%$ & $11,44 \%$ & $19,02 \%$ & $6,77 \%$ & $13,66 \%$ & $9,12 \%$ & $10,49 \%$ & $10,49 \%$ & $11,67 \%$ & $14,37 \%$ \\
\hline & $\mathrm{M}$ & $12,3 \%$ & $9,67 \%$ & $27,52 \%$ & $9,67 \%$ & $12,3 \%$ & $9,59 \%$ & $12,57 \%$ & $8,15 \%$ & $11,46 \%$ & $14,19 \%$ \\
\hline
\end{tabular}

Fuente: elaboración propia con base en SPADIEs [20]

Algunos casos que han reportado deserción entre 20 y $30 \%$ son: Universidad de La Guajira, Universidad de Sucre, Universidad del Pacífico, Universidad Militar Nueva Granada, Universidad Nacional de Colombia-Sede Bogotá y Universidad Tecnológica del Chocó. Las universidades que reportaron una deserción de más del 30\% son: Universidad de Nariño, Universidad del Pacífico y Universidad Militar Nueva Granada.

\section{Estadísticas de deserción en pregrados de Ingeniería a nivel mundial}

Según la Unesco [23], la educación terciaria refuerza los conocimientos impartidos en la enseñanza secundaria, proporcionando actividades de aprendizaje en campos especializados de la educación con el objetivo de desarrollar el aprendizaje a un alto nivel de complejidad y especialización. La educación terciaria incluye lo que habitualmente se conoce como educación académica, y también considera la educación vocacional o profesional avanzada. Los datos trabajados se encuentran en el periodo comprendido entre el 2010 y el 2015 en los países de América Latina y el Caribe, y se relacionan en la tabla 6.

Según los datos tratados, la mayoría de estudiantes que logran culminar sus estudios de educación terciaria con éxito en las carreras de Ingeniería se encuentran concentrados en Austria, Colombia y México. La acumulación de más periodos de estudiantes graduados se encuentra en Austria, como puede observarse en la tabla 6 y en la figura 19.

Tabla 6. Estadísticas de estudiantes graduados de carreras de Ingeniería en países a nivel mundial.

\begin{tabular}{lcccccc}
\hline \multicolumn{1}{c}{ País } & $\mathbf{2 0 1 0}$ & $\mathbf{2 0 1 1}$ & $\mathbf{2 0 1 2}$ & $\mathbf{2 0 1 3}$ & $\mathbf{2 0 1 4}$ & $\mathbf{2 0 1 5}$ \\
\hline Argentina & $6,65 \%$ & $6,66 \%$ & $\mathrm{~S} / \mathrm{D}$ & $\mathrm{S} / \mathrm{D}$ & $\mathrm{S} / \mathrm{D}$ & $\mathrm{S} / \mathrm{D}$ \\
Austria & $19,88 \%$ & $18,26 \%$ & $17,19 \%$ & $19,43 \%$ & $21,49 \%$ & $19,68 \%$ \\
Brasil & $6,84 \%$ & $6,98 \%$ & $7,71 \%$ & $\mathrm{~S} / \mathrm{D}$ & $10,13 \%$ & $\mathrm{~S} / \mathrm{D}$ \\
Bulgaria & $16,18 \%$ & $15,6 \%$ & $17,46 \%$ & $16,14 \%$ & $16,08 \%$ & $14,02 \%$ \\
Chequia & $14,86 \%$ & $13,66 \%$ & $13,09 \%$ & $13,6 \%$ & $13,21 \%$ & $14,49 \%$ \\
Chile & $15,3 \%$ & $\mathrm{~S} / \mathrm{D}$ & $14,62 \%$ & $14,77 \%$ & $15,31 \%$ & $\mathrm{~S} / \mathrm{D}$ \\
Chipre & $6,41 \%$ & $8,58 \%$ & $13,53 \%$ & $11,49 \%$ & $10,72 \%$ & $11,35 \%$ \\
Colombia & $\mathrm{S} / \mathrm{D}$ & $18,06 \%$ & $17,74 \%$ & $\mathrm{~S} / \mathrm{D}$ & $16,41 \%$ & $16,02 \%$ \\
Costa Rica & $5,7 \%$ & $6,74 \%$ & $\mathrm{~S} / \mathrm{D}$ & $\mathrm{S} / \mathrm{D}$ & $\mathrm{S} / \mathrm{D}$ & 7,125 \\
Ecuador & $\mathrm{S} / \mathrm{D}$ & $\mathrm{S} / \mathrm{D}$ & $\mathrm{S} / \mathrm{D}$ & $\mathrm{S} / \mathrm{D}$ & $9,65 \%$ & $\mathrm{~S} / \mathrm{D}$ \\
\hline
\end{tabular}


(viene)

\begin{tabular}{lcccccc}
\hline \multicolumn{1}{c}{ País } & $\mathbf{2 0 1 0}$ & $\mathbf{2 0 1 1}$ & $\mathbf{2 0 1 2}$ & $\mathbf{2 0 1 3}$ & $\mathbf{2 0 1 4}$ & $\mathbf{2 0 1 5}$ \\
\hline El Salvador & $11,08 \%$ & $9,11 \%$ & $9,37 \%$ & $\mathrm{~S} / \mathrm{D}$ & $\mathrm{S} / \mathrm{D}$ & $9,88 \%$ \\
Guatemala & $\mathrm{S} / \mathrm{D}$ & $\mathrm{S} / \mathrm{D} \%$ & $\mathrm{~S} / \mathrm{D}$ & $\mathrm{S} / \mathrm{D}$ & $\mathrm{S} / \mathrm{D}$ & $9,65 \%$ \\
Honduras & $10,06 \%$ & $\mathrm{~S} / \mathrm{D} \%$ & $9,98 \%$ & $\mathrm{~S} / \mathrm{D}$ & $\mathrm{S} / \mathrm{D}$ & $10,35 \%$ \\
México & $19,4 \%$ & 21,28 & $\mathrm{~S} / \mathrm{D}$ & $22,3 \%$ & $22,96 \%$ & $\mathrm{~S} / \mathrm{D}$ \\
Panamá & $15,3 \%$ & $10,73 \%$ & $\mathrm{~S} / \mathrm{D}$ & $\mathrm{S} / \mathrm{D}$ & $\mathrm{S} / \mathrm{D}$ & $\mathrm{S} / \mathrm{D}$ \\
Uruguay & $7,81 \%$ & $\mathrm{~S} / \mathrm{D}$ & $\mathrm{S} / \mathrm{D}$ & $\mathrm{S} / \mathrm{D}$ & $\mathrm{S} / \mathrm{D}$ & $7,57 \%$ \\
\hline
\end{tabular}

${ }^{*}$ S/D: Dato no reportado

Fuente: elaboración propia con base en Unesco [23]

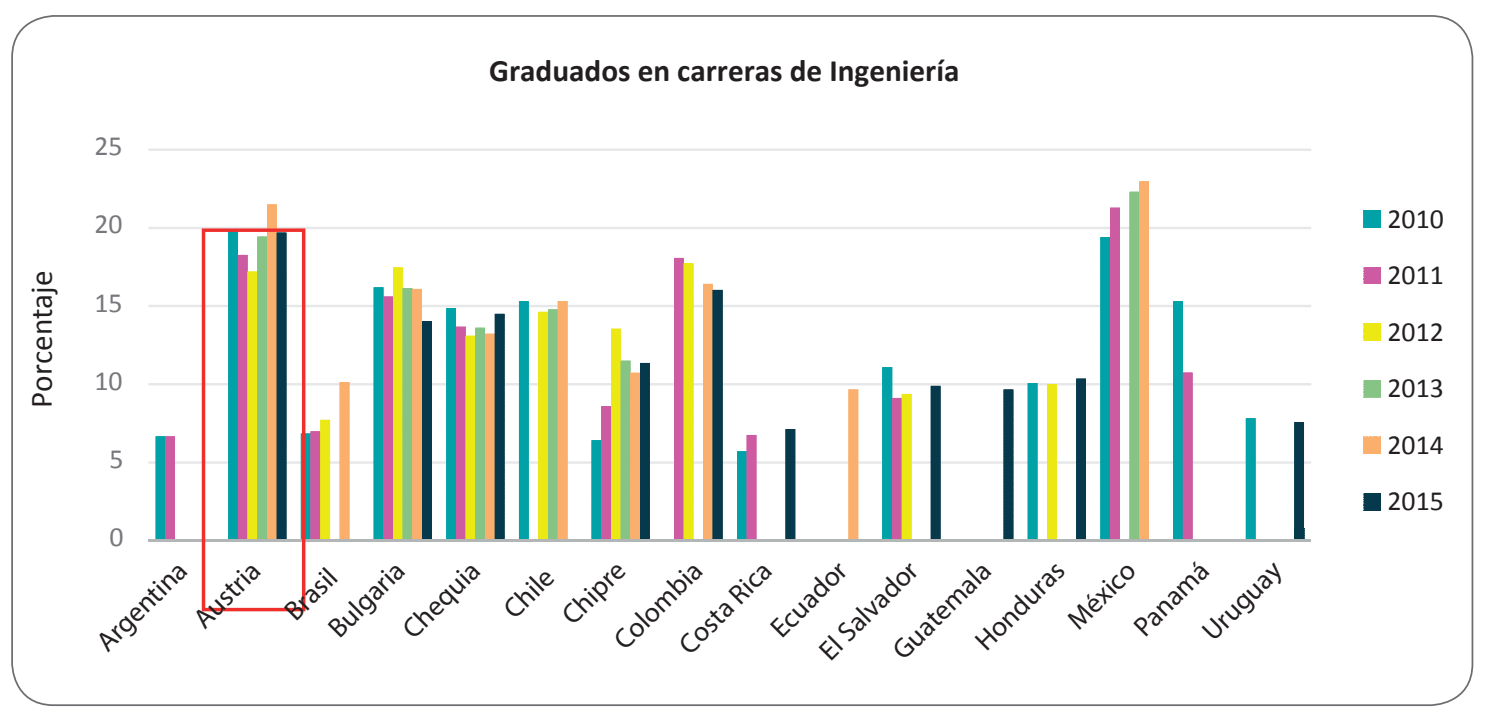

Figura 19. Porcentaje de graduados de las carreras de Ingeniería a nivel mundial por año y por país.

Fuente: elaboración propia con base en Unesco [23]

Así como en Colombia, los países de América Latina y el Caribe se han visto expuestos a un constante reto por mantener a sus jóvenes en la educación superior. En las Instituciones de Educación Superior, hay vacíos que de no ser cubiertos a tiempo pueden generar dificultades para que los jóvenes se adapten al sistema educativo. Según la Unesco [23], al año ingresan entre 53,43 y $65,65 \%$ de mujeres a la educación terciaria en programas curriculares de Ingeniería y afines, de las cuales culminan con éxito sus estudios entre 3,6 y 12,15\%, lo anterior soportado por las tablas 7, 8, 9 y 10.

Puede observarse que el mayor porcentaje de mujeres graduadas se encuentra en México, con $11,99 \%$. 
Tabla 7. Porcentaje de mujeres graduadas de las carreras de Ingeniería por año y país a nivel mundial.

\begin{tabular}{lcccccc}
\hline \multicolumn{1}{c}{ País } & $\mathbf{2 0 1 0}$ & $\mathbf{2 0 1 1}$ & $\mathbf{2 0 1 2}$ & $\mathbf{2 0 1 3}$ & $\mathbf{2 0 1 4}$ & $\mathbf{2 0 1 5}$ \\
\hline Argentina & $3,6 \%$ & $\mathrm{~S} / \mathrm{D}$ & $\mathrm{S} / \mathrm{D}$ & $\mathrm{S} / \mathrm{D}$ & $\mathrm{S} / \mathrm{D}$ & $\mathrm{S} / \mathrm{D}$ \\
Austria & $7,4 \%$ & $7,13 \%$ & $6,63 \%$ & $7,69 \%$ & $8,84 \%$ & $7,51 \%$ \\
Brasil & $3,42 \%$ & $3,59 \%$ & $4,03 \%$ & $\mathrm{~S} / \mathrm{D}$ & $5,84 \%$ & $\mathrm{~S} / \mathrm{D}$ \\
Bulgaria & $9,73 \%$ & $9,48 \%$ & $10,55 \%$ & $9,52 \%$ & $9,45 \%$ & $6,83 \%$ \\
Chequia & $6,44 \%$ & $6,44 \%$ & $6,43 \%$ & $6,7 \%$ & $6,8 \%$ & $7,66 \%$ \\
Chile & $5,34 \%$ & $\mathrm{~S} / \mathrm{D}$ & $5,03 \%$ & $4,8 \%$ & $4,92 \%$ & $\mathrm{~S} / \mathrm{D}$ \\
Chipre & $3,17 \%$ & $4,54 \%$ & $11,46 \%$ & $5,49 \%$ & $4,97 \%$ & $5,77 \%$ \\
Colombia & $\mathrm{S} / \mathrm{D}$ & $10,46 \%$ & $10,34 \%$ & $\mathrm{~S} / \mathrm{D}$ & $9,91 \%$ & $9,62 \%$ \\
Costa Rica & $2,59 \%$ & $3,68 \%$ & $\mathrm{~S} / \mathrm{D}$ & $\mathrm{S} / \mathrm{D}$ & $\mathrm{S} / \mathrm{D}$ & $3,83 \%$ \\
Ecuador & $\mathrm{S} / \mathrm{D}$ & $\mathrm{S} / \mathrm{D}$ & $\mathrm{S} / \mathrm{D}$ & $\mathrm{S} / \mathrm{D}$ & $3,52 \%$ & $\mathrm{~S} / \mathrm{D}$ \\
El Salvador & $3,85 \%$ & $3,01 \%$ & $3,08 \%$ & $\mathrm{~S} / \mathrm{D}$ & $\mathrm{S} / \mathrm{D}$ & $3,32 \%$ \\
Guatemala & $\mathrm{S} / \mathrm{D}$ & $\mathrm{S} / \mathrm{D}$ & $\mathrm{S} / \mathrm{D}$ & $\mathrm{S} / \mathrm{D}$ & $\mathrm{S} / \mathrm{D}$ & $3,73 \%$ \\
Honduras & $\mathrm{S} / \mathrm{D}$ & $\mathrm{S} / \mathrm{D}$ & $5,81 \%$ & $\mathrm{~S} / \mathrm{D}$ & $\mathrm{S} / \mathrm{D}$ & $5,89 \%$ \\
México & $10,08 \%$ & $11,34 \%$ & $\mathrm{~S} / \mathrm{D}$ & $11,99 \%$ & $12,15 \%$ & $\mathrm{~S} / \mathrm{D}$ \\
Panamá & $8,7 \%$ & $8,36 \%$ & $\mathrm{~S} / \mathrm{D}$ & $\mathrm{S} / \mathrm{D}$ & $\mathrm{S} / \mathrm{D}$ & $\mathrm{S} / \mathrm{D}$ \\
Uruguay & $5,27 \%$ & $\mathrm{~S} / \mathrm{D}$ & $\mathrm{S} / \mathrm{D}$ & $\mathrm{S} / \mathrm{D}$ & $\mathrm{S} / \mathrm{D}$ \\
\hline
\end{tabular}

${ }^{*}$ S/D: Dato no reportado

Fuente: elaboración propia con base en Unesco [23]

Tabla 8. Porcentaje de deserción femenina en carreras de Ingeniería a nivel mundial.

\begin{tabular}{lcccccc}
\hline \multicolumn{1}{c}{ País } & $\mathbf{2 0 1 0}$ & $\mathbf{2 0 1 1}$ & $\mathbf{2 0 1 2}$ & $\mathbf{2 0 1 3}$ & $\mathbf{2 0 1 4}$ & $\mathbf{2 0 1 5}$ \\
\hline Argentina & $96,4 \%$ & $\mathrm{~S} / \mathrm{D}$ & $\mathrm{S} / \mathrm{D}$ & $\mathrm{S} / \mathrm{D}$ & $\mathrm{S} / \mathrm{D}$ & $\mathrm{S} / \mathrm{D}$ \\
Austria & $92,6 \%$ & $92,87 \%$ & $93,37 \%$ & $92,31 \%$ & $91,16 \%$ & $92,49 \%$ \\
Brasil & $96,58 \%$ & $96,41 \%$ & $95,97 \%$ & $\mathrm{~S} / \mathrm{D}$ & $94,16 \%$ & $\mathrm{~S} / \mathrm{D}$ \\
Bulgaria & $90,27 \%$ & $90,52 \%$ & $89,45 \%$ & $90,48 \%$ & $90,55 \%$ & $93,17 \%$ \\
Chequia & $93,56 \%$ & $93,56 \%$ & $93,57 \%$ & $93,3 \%$ & $93,2 \%$ & $92,34 \%$ \\
Chile & $94,66 \%$ & $\mathrm{~S} / \mathrm{D}$ & $94,97 \%$ & $95,2 \%$ & $95,08 \%$ & $\mathrm{~S} / \mathrm{D}$ \\
Chipre & $96,83 \%$ & $95,46 \%$ & $88,54 \%$ & $94,51 \%$ & $95,03 \%$ & $94,23 \%$ \\
Colombia & $\mathrm{S} / \mathrm{D}$ & $89,54 \%$ & $89,66 \%$ & $\mathrm{~S} / \mathrm{D}$ & $90,09 \%$ & $90,38 \%$ \\
Costa Rica & $97,41 \%$ & $96,32 \%$ & $\mathrm{~S} / \mathrm{D}$ & $\mathrm{S} / \mathrm{D}$ & $\mathrm{S} / \mathrm{D}$ & $96,17 \%$ \\
Ecuador & $\mathrm{S} / \mathrm{D}$ & $\mathrm{S} / \mathrm{D}$ & $\mathrm{S} / \mathrm{D}$ & $\mathrm{S} / \mathrm{D}$ & $96,48 \%$ & $\mathrm{~S} / \mathrm{D}$ \\
El Salvador & $96,15 \%$ & $96,99 \%$ & $96,92 \%$ & $\mathrm{~S} / \mathrm{D}$ & $\mathrm{S} / \mathrm{D}$ & $96,68 \%$ \\
Guatemala & $\mathrm{S} / \mathrm{D}$ & $\mathrm{S} / \mathrm{D}$ & $\mathrm{S} / \mathrm{D}$ & $\mathrm{S} / \mathrm{D}$ & $\mathrm{S} / \mathrm{D}$ & $96,27 \%$ \\
Honduras & $\mathrm{S} / \mathrm{D}$ & $\mathrm{S} / \mathrm{D}$ & $94,19 \%$ & $\mathrm{~S} / \mathrm{D}$ & $\mathrm{S} / \mathrm{D}$ & $94,11 \%$ \\
México & $89,92 \%$ & $88,66 \%$ & $\mathrm{~S} / \mathrm{D}$ & $88,01 \%$ & $87,85 \%$ & $\mathrm{~S} / \mathrm{D}$ \\
Panamá & $91,3 \%$ & $91,64 \%$ & $\mathrm{~S} / \mathrm{D}$ & $\mathrm{S} / \mathrm{D}$ & $\mathrm{S} / \mathrm{D}$ & $\mathrm{S} / \mathrm{D}$ \\
Uruguay & $94,73 \%$ & $\mathrm{~S} / \mathrm{D}$ & $\mathrm{S} / \mathrm{D}$ & $\mathrm{S} / \mathrm{D}$ & $\mathrm{S} / \mathrm{D}$
\end{tabular}


El nivel de graduados es mayor en hombres que en mujeres, y por lo tanto los niveles de deserción son menores, como puede observarse en las tablas 9 y 10.
El mayor porcentaje de graduados hombres está concentrado en Austria y México, mientras que los mayores niveles de deserción se encuentran en Brasil, Costa Rica y Chipre.

Tabla 9. Porcentaje de hombres graduados de las carreras de Ingeniería por año y país a nivel mundial.

\begin{tabular}{lcccccc}
\hline \multicolumn{1}{c}{ País } & $\mathbf{2 0 1 0}$ & $\mathbf{2 0 1 1}$ & $\mathbf{2 0 1 2}$ & $\mathbf{2 0 1 3}$ & $\mathbf{2 0 1 4}$ & $\mathbf{2 0 1 5}$ \\
\hline Argentina & 12,25 & $\mathrm{~S} / \mathrm{D}$ & $\mathrm{S} / \mathrm{D}$ & $\mathrm{S} / \mathrm{D}$ & $\mathrm{S} / \mathrm{D}$ & $\mathrm{S} / \mathrm{D}$ \\
Austria & 33,14 & 30,85 & 30,11 & 34,37 & 37,24 & 34,76 \\
Brasil & 12,06 & 12,23 & 13,41 & $\mathrm{~S} / \mathrm{D}$ & 16,74 & $\mathrm{~S} / \mathrm{D}$ \\
Bulgaria & 26,09 & 25,23 & 27,64 & 26,36 & 26,01 & 24,88 \\
Chequia & 27,56 & 25,55 & 24,04 & 24,73 & 22,87 & 24,96 \\
Chile & 27,56 & $\mathrm{~S} / \mathrm{D}$ & 26,78 & 27,76 & 28,97 & $\mathrm{~S} / \mathrm{D}$ \\
Chipre & 11,27 & 13,99 & 16,67 & 20,9 & 20,47 & 21,12 \\
Colombia & $\mathrm{S} / \mathrm{D}$ & 27,15 & 26,44 & $\mathrm{~S} / \mathrm{D}$ & 24,58 & 23,9 \\
Costa Rica & 11,06 & 12,15 & $\mathrm{~S} / \mathrm{D}$ & $\mathrm{S} / \mathrm{D}$ & $\mathrm{S} / \mathrm{D}$ & 12,71 \\
Ecuador & $\mathrm{S} / \mathrm{D}$ & $\mathrm{S} / \mathrm{D}$ & $\mathrm{S} / \mathrm{D}$ & $\mathrm{S} / \mathrm{D}$ & 18,33 & $\mathrm{~S} / \mathrm{D}$ \\
El Salvador & 21,39 & 17,79 & 18,13 & $\mathrm{~S} / \mathrm{D}$ & $\mathrm{S} / \mathrm{D}$ & 18,46 \\
Guatemala & $\mathrm{S} / \mathrm{D}$ & $\mathrm{S} / \mathrm{D}$ & $\mathrm{S} / \mathrm{D}$ & $\mathrm{S} / \mathrm{D}$ & $\mathrm{S} / \mathrm{D}$ & 11,5 \\
Honduras & $\mathrm{S} / \mathrm{D}$ & $\mathrm{S} / \mathrm{D}$ & 17,84 & $\mathrm{~S} / \mathrm{D}$ & $\mathrm{S} / \mathrm{D}$ & 18,45 \\
México & 30,53 & 32,88 & $\mathrm{~S} / \mathrm{D}$ & 33,96 & 34,99 & S/D \\
Panamá & 27,25 & 14,89 & S/D & S/D & S/D & S/D \\
Uruguay & 12,37 & S/D & S/D & S/D & S/D & S/D \\
\hline
\end{tabular}

${ }^{\star}$ S/D: Dato no reportado

Fuente: elaboración propia con base en Unesco [23]

Tabla 10. Porcentaje de deserción masculina en carreras de Ingeniería a nivel mundial.

\begin{tabular}{lcccccc}
\hline \multicolumn{1}{c}{ País } & $\mathbf{2 0 1 0}$ & $\mathbf{2 0 1 1}$ & $\mathbf{2 0 1 2}$ & $\mathbf{2 0 1 3}$ & $\mathbf{2 0 1 4}$ & $\mathbf{2 0 1 5}$ \\
\hline Argentina & $87,75 \%$ & $\mathrm{~S} / \mathrm{D}$ & $\mathrm{S} / \mathrm{D}$ & $\mathrm{S} / \mathrm{D}$ & $\mathrm{S} / \mathrm{D}$ & $\mathrm{S} / \mathrm{D}$ \\
Austria & 66,865 & $69,15 \%$ & $69,89 \%$ & $65,63 \%$ & $62,76 \%$ & $65,24 \%$ \\
Brasil & $87,94 \%$ & $87,77 \%$ & $86,59 \%$ & $\mathrm{~S} / \mathrm{D}$ & $83,26 \%$ & $\mathrm{~S} / \mathrm{D}$ \\
Bulgaria & $73,91 \%$ & $74,77 \%$ & $72,36 \%$ & $73,64 \%$ & $73,99 \%$ & $75,12 \%$ \\
Chequia & $72,44 \%$ & $74,45 \%$ & $75,96 \%$ & $75,27 \%$ & $77,13 \%$ & $75,04 \%$ \\
Chile & $72,44 \%$ & $\mathrm{~S} / \mathrm{D}$ & $73,22 \%$ & $72,24 \%$ & $71,03 \%$ & $\mathrm{~S} / \mathrm{D}$ \\
Chipre & $88,73 \%$ & $86,01 \%$ & $83,33 \%$ & $79,1 \%$ & $79,53 \%$ & $78,88 \%$ \\
Colombia & $\mathrm{S} / \mathrm{D}$ & $72,85 \%$ & $73,56 \%$ & $\mathrm{~S} / \mathrm{D}$ & $75,42 \%$ & $76,1 \%$ \\
Costa Rica & $88,94 \%$ & $87,85 \%$ & $\mathrm{~S} / \mathrm{D}$ & $\mathrm{S} / \mathrm{D}$ & $\mathrm{S} / \mathrm{D}$ & $87,29 \%$ \\
Ecuador & $\mathrm{S} / \mathrm{D}$ & $\mathrm{S} / \mathrm{D}$ & $\mathrm{S} / \mathrm{D}$ & $\mathrm{S} / \mathrm{D}$ & $81,67 \%$ & $\mathrm{~S} / \mathrm{D}$ \\
El Salvador & $78,61 \%$ & $82,21 \%$ & $81,87 \%$ & $\mathrm{~S} / \mathrm{D}$ & $\mathrm{S} / \mathrm{D}$ & $81,54 \%$ \\
\hline
\end{tabular}


(viene)

\begin{tabular}{lcccccc}
\hline \multicolumn{1}{c}{ País } & $\mathbf{2 0 1 0}$ & $\mathbf{2 0 1 1}$ & $\mathbf{2 0 1 2}$ & $\mathbf{2 0 1 3}$ & $\mathbf{2 0 1 4}$ & $\mathbf{2 0 1 5}$ \\
\hline Guatemala & $\mathrm{S} / \mathrm{D}$ & $\mathrm{S} / \mathrm{D}$ & $\mathrm{S} / \mathrm{D}$ & $\mathrm{S} / \mathrm{D}$ & $\mathrm{S} / \mathrm{D}$ & $\mathrm{S} / \mathrm{D}$ \\
Honduras & $\mathrm{S} / \mathrm{D}$ & $\mathrm{S} / \mathrm{D}$ & $82,16 \%$ & $\mathrm{~S} / \mathrm{D}$ & $\mathrm{S} / \mathrm{D}$ & $81,55 \%$ \\
México & $69,47 \%$ & $67,12 \%$ & $\mathrm{~S} / \mathrm{D}$ & $66,04 \%$ & $65,01 \%$ & $\mathrm{~S} / \mathrm{D}$ \\
Panamá & $72,75 \%$ & $85,11 \%$ & $\mathrm{~S} / \mathrm{D}$ & $\mathrm{S} / \mathrm{D}$ & $\mathrm{S} / \mathrm{D}$ & $\mathrm{S} / \mathrm{D}$ \\
Uruguay & $87,63 \%$ & $\mathrm{~S} / \mathrm{D}$ & $\mathrm{S} / \mathrm{D}$ & $\mathrm{S} / \mathrm{D}$ & $\mathrm{S} / \mathrm{D}$ & $\mathrm{S} / \mathrm{D}$ \\
\hline
\end{tabular}

${ }^{*}$ S/D: Dato no reportado

Fuente: elaboración propia con base en Unesco [23]

Los mayores niveles de deserción en las carreras de Ingeniería se encuentran concentrados en Argentina, Chipre y Costa Rica con porcentajes de $93,35 \%, 93,59 \%$ y $94,3 \%$, respectivamente, como se observa en la figura 20.

\section{Discusión}

Países americanos se han comprometido a actualizar y a reestructurar el sistema de educación. Durante los años noventa, se lograron cambios y avances significativos en la implementación de políticas pedagógicas eficaces, en función de la dinámica y los "cambios económicos, la equidad social, la diversidad cultural y la democratización política", definiéndose como un proceso constante en las mejoras educacionales futuras, aclarando que el progreso de los niveles educativos varía según la ubicación geográfica, de acuerdo con lo reportado por la Unesco [24] y por Jacinto et al. [25].

La formación en educación superior es el camino de transformación para los países. Capacitar a los jóvenes implica desarrollar ciudadanos potenciales que contribuyan al desarrollo socioeconómico y sociocultural. Las diferentes problemáticas que enfrentan los jóvenes con el constante cambio del mundo van en incremento, y prefieren la vinculación al mundo laboral antes de capacitarse y formarse y ser potencialmente más atractivos para el mercado.

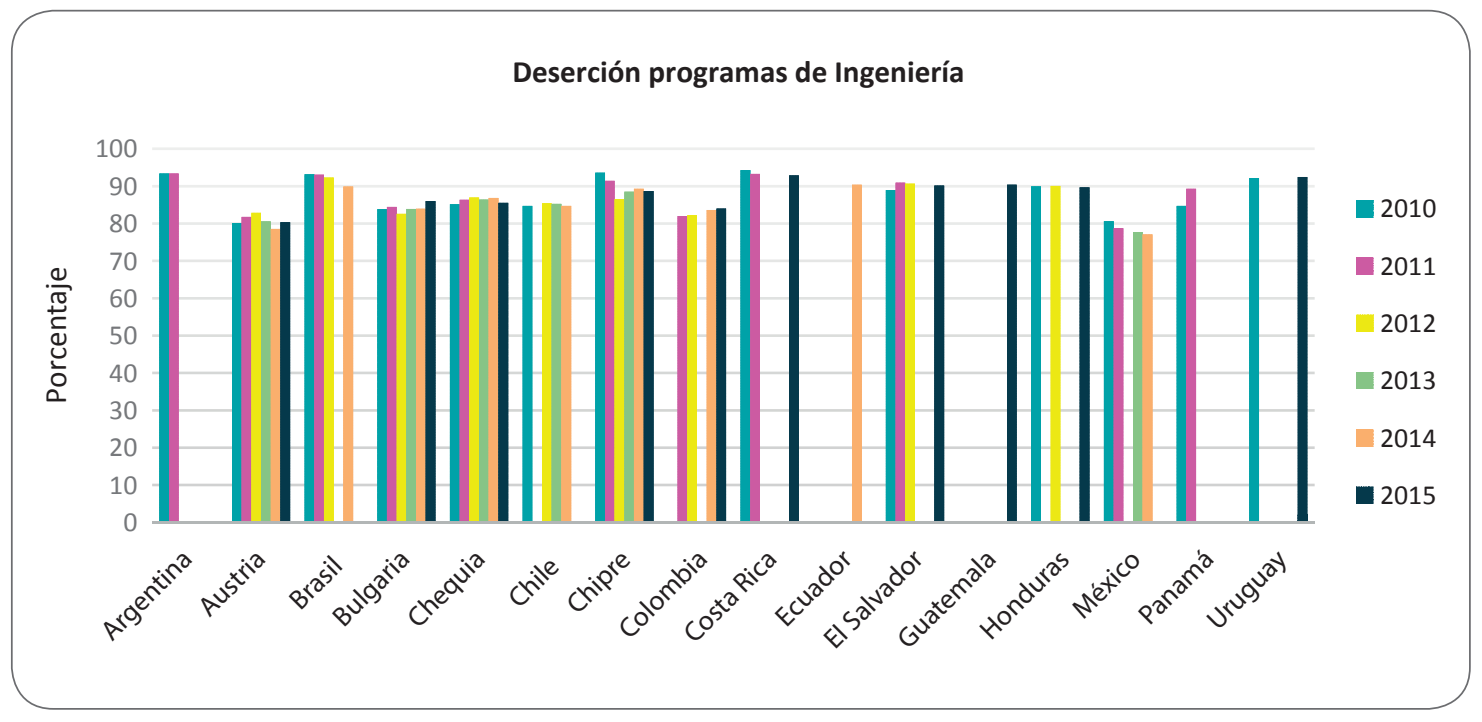

Figura 20. Deserción total de programas de Ingeniería - Visión internacional.

Fuente: elaboración propia con base en Unesco [23] 
Según estudios que abordan esta problemática, como el de la Universidad Nacional de Cuyo (Argentina), concluyen que los individuos que no terminan sus estudios están en una situación más vulnerable que los graduados. Tal situación podría mejorar implementando programas de apoyo para ayudar a los estudiantes a superar motivaciones y dificultades emocionales y que puedan graduarse. Aunque un título no garantiza un posicionamiento en el mundo profesional, se aumentan las posibilidades individuales de éxito y la perspectiva de calidad organizacional [25]. Entre las propuestas para las universidades en general está la de crear un aplicativo similar al sNIEs, con el que se tenga un seguimiento en tiempo real de los casos de deserción para proponer y diseñar políticas para la mitigación de este flagelo en las carreras del área de Ingeniería como tema central.

\section{Conclusiones y trabajos futuros}

Se pudo comprobar en los datos tratados que la mayor deserción se presenta en los primeros cuatro periodos académicos, lo que valida la información presentada en base teórica de la presente investigación. Se evidencia que la principal causa de deserción en los hombres de la Facultad de Ingeniería en el periodo comprendido entre 2016-I y 2017-I fue el factor económico, con una tasa de representación entre 81 y $88 \%$, y para el caso de las mujeres de la Facultad de Ingeniería corresponde al cambio de carrera.

La presente investigación permite evidenciar la necesidad que tienen las universidades de crear una base compacta de la información de cada uno de los estudiantes que ingresan a sus proyectos curriculares, recordando que la efectividad de esta puede mejorar una vez se tenga conocimiento completo de la documentación y se puedan centralizar sus tareas.

La importancia del seguimiento de cada uno de los factores fortalece el análisis estadístico, basado en información veraz y oportuna que permita medir y cuantificar los niveles de incorporación y de deserción de la universidad, los cuales permitirían proponer políticas de mitigación a este flagelo.

\section{Referencias}

[1] Universidad Pedagógica Nacional (UPN), La deserción estudiantil: Reto investigativo y estratégico asumido de forma integral por la UPN. Bogotá: Universidad Pedagógica Nacional, 2005, pp. 1-10 [En línea]. Disponible en: http://www.mineducacion. gov.co/1621/articles-85600_Archivo_pdf3.pdf.

[2] Ministerio de Educación Nacional, 'Reconectados', para evitar la deserción estudiantil. Bogotá: Ministerio de Educación, 2015 [En línea]. Disponible en: https://www.mineducacion.gov.co/cvn/1665/article-100028.html.

[3] R. Meléndez, Estudio sobre deserción y permanencia académica en la Facultad de Ingeniería de la Universidad de La Guajira desde el II PA 2005 hasta el II PA 2007. Riohacha: Ministerio de Educación, 2008 [En línea]. Disponible en: http://www.colombiaaprende. edu.co/html/micrositios/1752/articles-323174_recurso_1.pdf.

[4] A. Corengia, M. Pita, B. Mesurado y A. Centeno, "Predicting Academic Performance and Attrition in Undergraduate Students". Liberabit. Revista de Psicología, vol. 1, no. 9, pp. 101-112, 2013 [En línea]. Disponible en: http://www.scielo.org.pe/pdf/liber/ v19n1/a10v19n1.pdf.

[5] Unesco, Policy Paper for Change and Development in Higher Education. París: Unesco, 1995 [En línea]. Disponible en: http://unesdoc.unesco.org/images/ 0009/000989/098992e.pdf.

[6] Unesco, Data Availability for the Calculation of SDG 4-Education 2030 Indicators. Analysis Covering Latin America and the Caribbean. Québec: Unesco, 2016 [En línea]. Disponible en: http://unesdoc.unesco. org/images/0024/002462/246263e.pdf.

[7] N. Varghese, Globalization of Higher Education and Cross-Border Student Mobility. París: Unesco, 2008 [En línea]. Disponible en: http://unesdoc.unesco. org/images/0015/001579/157989e.pdf.

[8] M. Rossi, "Factors Affecting Academic Performance of University Evening Students Santiago de Chile". Journal of Education and Human Development, vol. 6, no. 1, pp. 96-102, 2017, doi: https://doi. org/10.15640/jehd.v6n1a10.

[9] E. Hazelkorn, Impact of Global Rankings on Higher Education Research and the Production of Knowledge. París: Unesco, 2009 [En línea]. Disponible en: http:// unesdoc.unesco.org/images/0018/001816/181653e. pdf.

[10] Naciones Unidas, Desarrollo sostenible en América Latina y el Caribe: seguimiento de la agenda de 
las Naciones Unidas para el desarrollo pos-2015 y Río+20. Santiago: Comisión Económica para América Latina y el Caribe (Cepal) y Grupo de las Naciones Unidas para el Desarrollo - América Latina y el Caribe (Undg LAC), 2013. [En línea]. Disponible en: https://www.cepal.org/rio20/noticias/paginas/6/43766/2013-272Rev.1_Desarrollo_sostenible_en_America_Latina_y_el_Caribe_WEB.pdf

[11] L. Patiño-Garzón y A. M. Cardona-Pérez, "Revisión de algunos estudios sobre la deserción estudiantil universitaria en Colombia y Latinoamérica", Theoria, vol. 21, no. 1, pp. 9-20, 2012. [En línea]. Disponible en: http://www.redalyc.org/articulo.oa?id= 29931769002.

[12] G. Sánchez, S. Navarro y A. García, Factores de deserción estudiantil en la Universidad Surcolombiana. Bogotá: Paideia, 2009 [En línea]. Disponible en: https://www.journalusco.edu.co/index.php/paideia/ article/view/1083/2108.

[13] M. Carvajal, Causas académicas de la deserción estudiantil. Medellín: Fundación Universitaria Católica del Norte, 2012 [En línea]. Disponible en: http:// www.ucn.edu.co/institucion/Documents/foro\%20 sobre\%20desercion/3-causas-academicas-de-la-desercion.pdf.

[14] Icfes y Universidad Nacional de Colombia, Estudio de la deserción estudiantil en la educación superior en Colombia. Documento sobre estado del arte. Bogotá: Icfes, 2002 [En línea]. Disponible en: https:// www.mineducacion.gov.co/sistemasdeinformacion/1735/articles-254702_libro_desercion.pdf.

[15] R. Ferrel, A. Celis y O. Hernández, "Depresión y factores sociodemográficos asociados en estudiantes universitarios de ciencias de la salud de una universidad publica (Colombia)”. Psicología desde el Caribe, no. 27, pp. 40-60, enero-junio 2011 [En línea]. Disponible en: http://www.scielo.org.co/pdf/ psdc/n27/n27a03.pdf.

[16] Sistema para la Prevención y Análisis de la Deserción en las Instituciones de Educación Superior (SPADIES), Glosario - Sistema para la Prevención de la Deserción en las Instituciones de Educación Superior. Bogotá: Ministerio de Educación, 2018 [En línea]. Disponible en: https://www.mineducacion.gov.co/ sistemasdeinformacion/1735/w3-article-254707. html.

[17] R. Quintero, Bajo rendimiento académico en la Universidad Distrital Francisco José de Caldas. Bogotá: Editorial Universidad Distrital, 2015.
[18] Sistema Nacional de Información de Educación Superior (sNIES), Sistema Nacional de Información de la Educación Superior. Bogotá: Ministerio de Educación Nacional, 2018 [En línea]. Disponible en: https://www.mineducacion.gov.co/sistemasinfo/ snies/.

[19] M. Malagón, L. Soto y P. Eslava, "La deserción en la Universidad de los Llanos (1998-2004)", Revista Orinoquia, vol. 11, no. 1, pp. 23-40, 2007, doi: https:// doi.org/10.22579/20112629.166.

[20] Sistema para la Prevención y Análisis de la Deserción en las Instituciones de Educación Superior (spadies), Sistema para la Prevención de la Deserción en la Educación Superior. Bogotá: Ministerio de Educación Nacional, 2017 [En línea]. Disponible en: https://www.mineducacion.gov.co/sistemasdeinformacion/1735/w3-article-363411.html

[21] M. L. Sánchez Arévalo, "Modelo representativo de deserción estudiantil voluntaria en carreras de pregrado de la Facultad de Ingeniería de la Universidad Distrital Francisco José de Caldas", Trabajo de grado, Univ. Distrital, Bogotá, Colombia, 2015 [En línea]. Disponible en: http://hdl.handle.net/11349/2939.

[22] Oficina Asesora de Sistemas de la Universidad Distrital Francisco José de Caldas (oAs), Reportes de autores según la plataforma de la Oficina Asesora de Sistemas-Condor. Bogotá: Editorial Universidad Distrital, 2015.

[23] Unesco, Distribution of Tertiary Graduates by Field of Education. París: Unesco, 2018 [En línea]. Disponible en: http://uis.unesco.org/indicator/edu-compl-grad-field.

[24] Unesco, Latin America and the Caribbean - Regional report. París: Unesco, 2001 [En línea]. Disponible en: http://uis.unesco.org/sites/default/files/documents/ regional-report-on-latin-america-and-the-caribbean-2001-en_0.pdf.

[25] C. Jacinto, J. Barato, P. Flores, A. García, C. Mendoza y C. Turbay, Incluir a los jóvenes. Retos para la educación terciaria técnica en América Latina, París: Unesco, 2013 [En línea]. Disponible en: http:// staffingamericalatina.com/incluir-a-los-jovenes-retos-para-la-educacion-terciaria-tecnica-en-america-latina/

[26] M. Aparicio, "Barriers to Learning, Achievement, Institutional Identities and Professionalization". Euro. J. Social Sciences Ed. and Research, vol. 06, no. 1, pp. 78-87, 2016, doi: http://dx.doi.org/10.26417/ ejser.v6i1.p78-87 